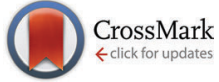

Cite this: DOI: $10.1039 / \mathrm{c5cp} 02001 \mathrm{~h}$

\title{
Mechanism of the hydroxyl radical oxidation of methacryloyl peroxynitrate (MPAN) and its pathway toward secondary organic aerosol formation in the atmosphere $\uparrow$
}

\author{
Tran B. Nguyen, ${ }^{* a}$ Kelvin H. Bates, ${ }^{b}$ John D. Crounse, ${ }^{a}$ Rebecca H. Schwantes, ${ }^{a}$ \\ Xuan Zhang, ${ }^{a}$ Henrik G. Kjaergaard, ${ }^{c}$ Jason D. Surratt, ${ }^{d}$ Peng Lin, ${ }^{e}$ Alexander Laskin, ${ }^{e}$ \\ John H. Seinfeld ${ }^{\text {bf }}$ and Paul O. Wennberg ${ }^{\text {af }}$
}

\begin{abstract}
Methacryloyl peroxynitrate (MPAN), the acyl peroxynitrate of methacrolein, has been suggested to be an important secondary organic aerosol (SOA) precursor from isoprene oxidation. Yet, the mechanism by which MPAN produces SOA through reaction with the hydroxyl radical $(\mathrm{OH})$ is unclear. We systematically evaluate three proposed mechanisms in controlled chamber experiments and provide the first experimental support for the theoretically-predicted lactone formation pathway from the MPAN $+\mathrm{OH}$ reaction, producing hydroxymethyl-methyl- $\alpha$-lactone (HMML). The decomposition of the MPAN-OH adduct yields $\mathrm{HMML}+\mathrm{NO}_{3}$ $(\sim 75 \%)$ and hydroxyacetone $+\mathrm{CO}+\mathrm{NO}_{3}(\sim 25 \%)$, out-competing its reaction with atmospheric oxygen. The production of other proposed SOA precursors, e.g., methacrylic acid epoxide (MAE), from MPAN and methacrolein are negligible $(<2 \%)$. Furthermore, we show that the beta-alkenyl moiety of MPAN is critical for lactone formation. Alkyl radicals formed cold via $\mathrm{H}$-abstraction by $\mathrm{OH}$ do not decompose to $\mathrm{HMML}$, even if they are structurally identical to the MPAN-OH adduct. The SOA formation from HMML, from polyaddition of the lactone to organic compounds at the particle interface or in the condensed phase, is close to unity under dry conditions. However, the SOA yield is sensitive to particle liquid water and solvated ions. In hydrated inorganic particles, $\mathrm{HMML}$ reacts primarily with $\mathrm{H}_{2} \mathrm{O}$ to produce the monomeric 2-methylglyceric acid (2MGA) or with aqueous sulfate and nitrate to produce the associated organosulfate and organonitrate, respectively. 2MGA, a tracer for isoprene SOA, is semivolatile and its accommodation in aerosol water decreases with decreasing $\mathrm{pH}$. Conditions that enhance the production of neutral 2MGA suppress SOA mass from the HMML channel. Considering the liquid water content and $\mathrm{pH}$ ranges of ambient particles, 2MGA will exist largely as a gaseous compound in some parts of the atmosphere.
\end{abstract}

Received 6th April 2015,

Accepted 11th June 2015

DOI: $10.1039 / \mathrm{c} 5 \mathrm{cp} 02001 \mathrm{~h}$

www.rsc.org/pccp oxidation of isoprene $\left(\mathrm{C}_{5} \mathrm{H}_{8}\right)$, arguably the most important nonmethane hydrocarbon emitted to the atmosphere, has a significant sensitivity to the $\mathrm{NO}_{x}$ conditions under which it is oxidized. This $\mathrm{NO}_{x}$ sensitivity translates to regional environmental impacts. For example, the high- $\mathrm{NO}_{x}$ oxidation of isoprene controls the production of tropospheric ozone in regions rich with biogenic hydrocarbons ${ }^{1-3}$ by accelerating the cycling of $\mathrm{NO}_{x}$ and producing $\mathrm{NO}_{x}$ reservoir species (e.g., organic nitrates and peroxynitrates). Isoprene chemistry also affects global climate primarily through the formation of secondary organic aerosol (SOA). ${ }^{4-7}$ However, the lingering uncertainties of SOA formation in various anthropogenically-impacted, but biogenically-influenced, systems preclude accurate simulations of human-induced climate and air quality feedbacks in atmospheric chemical transport models.

A common approach to identify the source of SOA is through tracer compounds, e.g., 2-methylglyceric acid $(2 \mathrm{MGA})^{9-11}$ in isoprene-derived ambient aerosols. 2MGA and its oligomers 


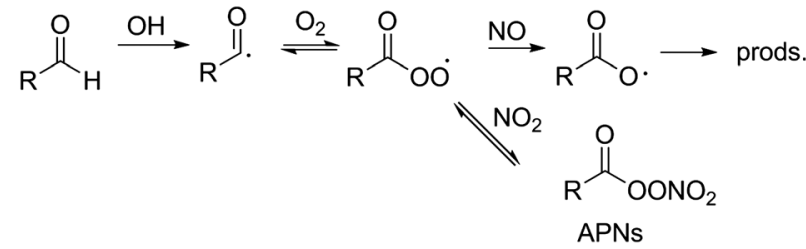

Fig. 1 The formation of acyl peroxynitrates (APNs) from the $\mathrm{OH}$-initiated oxidation of aldehydes is favoured under high $\mathrm{NO}_{2}$ to $\mathrm{NO}$ conditions. For methacrolein, the abstraction of the aldehydic $\mathrm{H}$ occurs roughly half of the time $^{8}$ in the $\mathrm{OH}$ oxidation reaction at room temperature.

are thought to be enhanced under high- $\mathrm{NO}_{x}$ conditions ${ }^{12-14}$ and, furthermore, can be uniquely traced to the oxidation of methacrolein, ${ }^{14,15}$ a first-generation isoprene oxidation product. Chan et al. ${ }^{13}$ showed that high- $\mathrm{NO}_{2}$ chemistry (as opposed to "high- $\mathrm{NO}_{x}$ " where most of the $\mathrm{NO}_{x}$ can be represented by $\mathrm{NO}$ ) favours the production of SOA via the acyl peroxynitrate channel (APN, Fig. 1). Essentially all of the SOA generated in the laboratory studies of the isoprene high- $\mathrm{NO}_{x}$ route was shown to be derived from methacrolein photochemistry, suggesting a major role of the APN from methacrolein, methacryloyl peroxynitrate (MPAN). The suggestion by Chan et al. was confirmed by the synthesis of MPAN and the measurement of its SOA formation through photochemistry (tested under high-NO conditions). ${ }^{16}$

Although the potential of MPAN $+\mathrm{OH}$ chemistry to produce SOA is relatively well established, the chemical mechanism leading to SOA from MPAN photooxidation has been subject of debate. It is also not clear whether the MPAN photooxidation is sensitive to $\mathrm{NO}_{x}$, although past studies have all been performed in the presence of NO. Fig. 2 shows three possible pathways leading to SOA production that have been proposed by independent works. ${ }^{13,17,18}$

The initial step of the MPAN photooxidation is $\mathrm{OH}$ addition to the double bond, primarily generating the energetically hot tertiary alkyl radical of MPAN (A*, Fig. 2). Chan et al., ${ }^{13}$ in a series of photochemical chamber experiments, proposed that the main fate of $\mathrm{A}^{*}$ is collisional stabilization (producing $\mathrm{A}$ ) followed by reaction with molecular oxygen to form an alkylperoxyl radical (B), where the beta-peroxyl moiety attacks at the carbonyl carbon to form a di-oxoketone (DOK) and $\mathrm{NO}_{2}$ as a co-product (Fig. 2, mechanism 2). The suggestion by Chan et al. was derived by performing methacrolein high- $\mathrm{NO}_{2}$ photooxidation experiments at low $\mathrm{O}_{2}$ content $(\sim 2 \%)$. The authors did not observe an increase in SOA yield and concluded that either $\mathrm{O}_{2}$ addition is required for SOA formation or is non-competitive at those levels.

From a combined suite of density functional theory and coupled cluster calculations, Kjaergaard et al. ${ }^{17}$ proposed a rapid ring closure from an acylperoxyl oxygen of $\mathrm{A}^{*}$ to form a 3-member lactone, hydroxymethyl-methyl- $\alpha$-lactone (HMML), and $\mathrm{NO}_{3}$ as a co-product (Fig. 2, mechanism 3). Furthermore, the authors hypothesize that a significant fraction of the HMML product $(36 \%)$ is generated with sufficient energy to further decompose to hydroxyacetone (HAC) and CO. Lin et al. ${ }^{18}$ also identified the formation of HMML via density functional theory calculations; however, they hypothesized that HMML may be too unstable to form in the atmosphere.

Lin et $a{ }^{18}{ }^{18}$ proposed a rapid $\mathrm{H}$-migration induced ring closure at the hydroxyl oxygen, via a 6-member intermediate, to an epoxide product called methacrylic acid epoxide (MAE, Fig. 2, mechanism 1). This suggestion was formulated by comparing the composition of SOA (e.g., 2MGA and other products) from the photooxidation of methacrolein and the reactive uptake of laboratory-synthesized MAE onto highly-acidic particles, as well as through quantum chemistry calculations. The mechanism of the uptake was suggested to be nucleophilic ring opening of the epoxide in an analogous reaction to the isoprene epoxydiols. ${ }^{19}$

Notable differences between the proposed pathways include: (1) the fate of $A^{*}$ - whether cyclization/decomposition occurs more rapidly than thermalization and, thus, bimolecular reaction with $\mathrm{O}_{2}$, (2) the stability of the products - MAE is the only product stable enough to be detected by current analytical instrumentation, and (3) the subsequent SOA formation mechanism under low humidity conditions - MAE requires highly-acidic seed aerosols to open the epoxide ring, while the

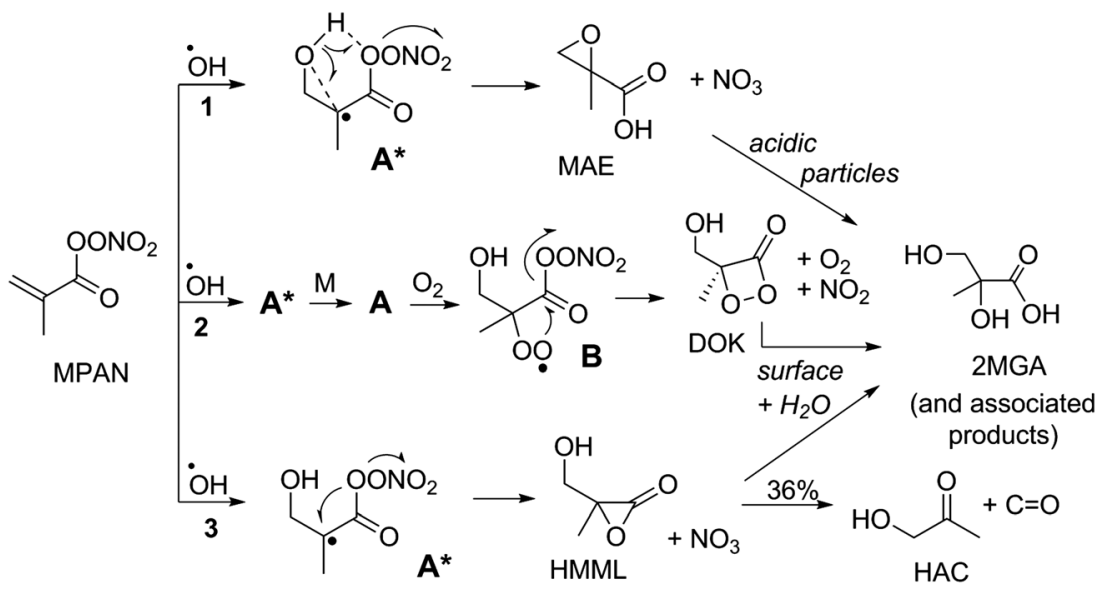

Fig. 2 The three proposed pathways to the formation of 2-methylglyceric acid (2MGA), a tracer for isoprene-derived ambient SOA. Mechanisms 1-3 and acronyms are discussed in the text. IUPAC names of key organic compounds discussed in this work are shown in Table S1 (ESI $\dagger$ ). 
ring opening of the more unstable compounds, DOK and HMML, would likely require only collisions with a surface.

The uncertainties in the MPAN $+\mathrm{OH}$ mechanism persist due to ambiguities from previous work. For example, earlier studies of the MPAN $+\mathrm{OH}$ system ${ }^{20,21}$ did not measure SOA formation and were conducted with high mixing ratios of $\mathrm{NO}_{x}$ (blind to the formation of nitrogen products). More-recent laboratory studies of Chan et $a l .{ }^{13}$ and Lin et al. ${ }^{18}$ were performed with methacrolein, such that products from MPAN oxidation and from the $\mathrm{OH}$ addition route of methacrolein ( $\sim 55 \%$ probability) were formed simultaneously, complicating the analysis. ${ }^{8}$ The theoretical study of Kjaergaard et al. ${ }^{17}$ has yet to be experimentally validated. In this work, we elucidate the chemical mechanism governing the MPAN photooxidation (and the photooxidation of its chemical analogues) through a series of targeted chamber experiments using laboratory-synthesized MPAN under low humidity and low-NO conditions. We further study the chemical pathway with which the MPAN produces SOA under simulated ambient conditions with higher relative humidity and seed particle concentrations.

\section{Experimental}

\section{Chamber studies}

The atmospheric chamber facility used for this work has been described in detail. ${ }^{22}$ A portion of the present work, namely, control experiments with $\alpha$-pinene and exploratory experiments with methacrolein, were performed as part of the Focused Isoprene eXperiment at the California Institute of Technology (FIXCIT) chamber campaign. ${ }^{22}$ Briefly, experiments were conducted in a large $\left(24 \mathrm{~m}^{3}\right)$ teflon chamber using purified dry air $(<5 \%$ relative humidity $(\mathrm{RH})$ at $298 \mathrm{~K})$ such that initial NO mixing ratios were lower than 100 pptv (measured by G. S. Tyndall, D. D. Montzka, and A. J. Weinheimer at FIXCIT) and initial particle mass concentrations were much lower than $0.01 \mu \mathrm{g} \mathrm{m} \mathrm{m}^{-3}$ (measured by
SMPS, see following text). For the experiments that were performed under humid conditions, water vapour was added to the chamber using a Nafion membrane humidifier (Perma Pure LLC) and recirculating ultrapure water (18 $\mathrm{M} \Omega$, Millipore Milli-Q). Particles were injected (mean particle diameter $\sim 70 \mathrm{~nm}$ ) by atomizing dilute solutions of ammonium sulfate $(0.1 \mathrm{M})$ through a heated wet-wall denuder to deliquesce the particles prior to entering the chamber held at $\mathrm{RH} 40 \%$ or $85 \%$. Corrections for the wall deposition of particles, using ammonium sulfate seed aerosols, were derived from control experiments performed at several water vapour mixing ratios in the chamber. Volatile organics, excluding MPAN, were injected by microliter syringe into a clean glass bulb and quantitatively transferred with dry nitrogen gas into the chamber through a short section of tubing, optionally with gentle heating for the larger hydrocarbons such as $\alpha$-pinene $\left(<80{ }^{\circ} \mathrm{C}\right)$. The temperature in the chamber enclosure was adjusted to 15-25 ${ }^{\circ} \mathrm{C}$ for experiments as needed. MPAN experiments were performed at $15{ }^{\circ} \mathrm{C}$ to minimize the thermal decomposition of MPAN (thermal lifetime $\sim 26 \mathrm{~h}$ at $15{ }^{\circ} \mathrm{C}$, compared to $\sim 5 \mathrm{~h}$ at $25{ }^{\circ} \mathrm{C}$, for an $\mathrm{NO}_{2} / \mathrm{NO}$ ratio of 10 that is representative of areas outside of urban centres). ${ }^{23}$

Table 1 lists the laboratory conditions for the main experiments in this work, e.g., the gas-phase oxidation of MPAN (synthesized standard), methacrolein (MACR, Aldrich, 95\%), isobutyraldehyde (ISOBUT, Aldrich, >99\%), and 2-methyl-but-3-ene-1-ol (231MBO, Aldrich, 98\%). Photochemistry under low-NO conditions $\left(\mathrm{HO}_{2}>\right.$ NO) was initiated by the near-UV $\left(300-400 \mathrm{~nm}, \lambda_{\max } \sim 350 \mathrm{~nm}\right)$ photolysis of gas-phase hydrogen peroxide that has been evaporated into the chamber (Aldrich, $50 \mathrm{wt} \%$ in water):

$$
\begin{gathered}
\mathrm{H}_{2} \mathrm{O}_{2}+h \nu \rightarrow \mathrm{OH}+\mathrm{OH} \\
\mathrm{OH}+\mathrm{H}_{2} \mathrm{O}_{2} \rightarrow \mathrm{HO}_{2}+\mathrm{H}_{2} \mathrm{O}
\end{gathered}
$$

Photochemistry under high $\mathrm{NO}_{2}$ (and typically lower in NO) conditions were initiated by the photolysis of gas-phase methyl

Table 1 Experimental conditions for the laboratory photooxidation of hydrocarbons (HC) used in this work: MPAN, methacrolein (MACR), isobutyraldehyde (ISOBUT) and 2-methyl-but-3-ene-1-ol (231MBO). The light intensity was $100 \%\left(\mathrm{JNO}_{2} \sim 7 \times 10^{-3} \mathrm{~s}^{-1}\right)$ for hydrogen peroxide (HP) experiments and $10-20 \%$ for methyl nitrite (MN) experiments. Steady state $\mathrm{OH}$ is estimated from hydrocarbon decay (GC) data. $\alpha$-pinene ( $\alpha$-Pin) and methacrylic acid epoxide (MAE) were added in select experiments to capture $\mathrm{NO}_{3}$ and observe SOA formation, respectively. Control experiments of $\mathrm{HP}+h \nu$, tridecane + $\mathrm{HP}+h \nu$, and wall losses (described in Experimental section) are not included in table. Experiments were performed at various temperature and relative

\begin{tabular}{|c|c|c|c|c|c|c|c|c|c|c|c|}
\hline \multirow{2}{*}{$\begin{array}{l}\text { Exp. } \\
\text { \# }\end{array}$} & \multicolumn{2}{|c|}{ HC precursor } & \multicolumn{2}{|l|}{ Oxidant } & \multirow[b]{2}{*}{$\begin{array}{l}{[\mathrm{OH}] \mathrm{SS}} \\
\left(\mathrm{cm}^{-3}\right)\end{array}$} & \multirow[b]{2}{*}{$\begin{array}{l}\text { Rxn } \\
\text { time (h) }\end{array}$} & \multirow[b]{2}{*}{$\begin{array}{l}\text { Temp. } \\
\left({ }^{\circ} \mathrm{C}\right)\end{array}$} & \multirow[b]{2}{*}{$\begin{array}{l}\text { RH } \\
(\%)\end{array}$} & \multirow[b]{2}{*}{$\begin{array}{l}{[\mathrm{NO}]_{0}} \\
(\mathrm{ppb})\end{array}$} & \multirow[b]{2}{*}{$\begin{array}{l}{\left[\mathrm{NO}_{2}\right]_{0}} \\
(\mathrm{ppb})\end{array}$} & \multirow[b]{2}{*}{ Additional injections } \\
\hline & Name & $\begin{array}{l}{[\mathrm{HC}]_{0}} \\
(\mathrm{ppb})\end{array}$ & Source & $\begin{array}{l}{[\mathrm{Ox}]_{0}} \\
(\mathrm{ppb})\end{array}$ & & & & & & & \\
\hline 1 & MPAN & 30 & $\mathrm{H}_{2} \mathrm{O}_{2}+h \nu$ & 2000 & $1.5 \times 10^{6}$ & 2.5 & 15 & $<5$ & $<0.1$ & 1 & $\alpha$-Pin (50 ppb) \\
\hline 2 & MPAN & 13 & $\mathrm{H}_{2} \mathrm{O}_{2}+h \nu$ & 2000 & $1.5 \times 10^{6}$ & 5 & 15 & $<5$ & $<0.1$ & 1 & - \\
\hline 3 & MPAN & 23 & $\mathrm{H}_{2} \mathrm{O}_{2}+h \nu$ & 2000 & $1.5 \times 10^{6}$ & 4.5 & 15 & $<5$ & $<0.1$ & 1 & - \\
\hline 4 & MPAN & 30 & $\mathrm{H}_{2} \mathrm{O}_{2}+h \nu$ & 2000 & $1.5 \times 10^{6}$ & 4.5 & 15 & $<5$ & $<0.1$ & 1 & $\alpha$-Pin (30 ppb) + MAE (15 ppb) \\
\hline 5 & MPAN & 17 & $\mathrm{H}_{2} \mathrm{O}_{2}+h \nu$ & 2000 & $1.5 \times 10^{6}$ & 3.2 & 15 & $<5$ & $<0.1$ & 1 & $\alpha$-Pin $(30 \mathrm{ppb})+\operatorname{MAE}(15 \mathrm{ppb})$ \\
\hline 6 & MACR & 100 & $\mathrm{H}_{2} \mathrm{O}_{2}+h \nu$ & 2000 & $1.5 \times 10^{6}$ & 5 & 15 & $<5$ & 10 & 230 & - \\
\hline 7 & MACR & 50 & $\mathrm{MN}+h \nu$ & 140 & $2 \times 10^{7}$ & 2.5 & 25 & $<5$ & $<0.1$ & 50 & - \\
\hline 8 & MACR & 80 & $\mathrm{MN}+h \nu$ & 130 & $1 \times 10^{7}$ & 2.5 & 15 & $<5$ & $<0.1$ & 110 & - \\
\hline 9 & MACR & 100 & $\mathrm{MN}+h \nu$ & 200 & $2 \times 10^{7}$ & 2.5 & 25 & $<5$ & 10 & 100 & - \\
\hline 10 & ISOBUT & 80 & $\mathrm{MN}+h \nu$ & 220 & $2 \times 10^{7}$ & 5.5 & 25 & $<5$ & 10 & 50 & - \\
\hline 11 & $231 \mathrm{MBO}$ & 200 & $\begin{array}{l}\mathrm{O}_{3}, \text { then } \\
\mathrm{MN}+h \nu\end{array}$ & $\begin{array}{l}\sim 600\left[\mathrm{O}_{3}\right] \\
200[\mathrm{MN}]\end{array}$ & $2 \times 10^{7}$ & 24 & 25 & $<5$ & 10 & 100 & - \\
\hline 12 & MACR & 200 & $\mathrm{MN}+h \nu$ & 200 & $2 \times 10^{7}$ & 3.5 & 25 & 40 & 10 & 100 & AS seeds \\
\hline 13 & MACR & 100 & $\mathrm{MN}+h \nu$ & 200 & $2 \times 10^{7}$ & 2.5 & 25 & 85 & 10 & 100 & AS seeds \\
\hline
\end{tabular}
humidity $(\mathrm{RH})$. Select experiments were performed with $\sim 80 \mu \mathrm{g} \mathrm{m}^{-3}$ of ammonium sulfate (AS) seed particles 
nitrite (synthesized standard, stored in liquid $\mathrm{N}_{2}$ ) in the presence of various mixing ratios of additional $\mathrm{NO}_{2}$ (standard mixture in $\mathrm{N}_{2}$ ).

$$
\begin{gathered}
\mathrm{CH}_{3} \mathrm{ONO}+h \nu+\mathrm{O}_{2} \rightarrow \mathrm{HO}_{2}+\mathrm{NO}+\mathrm{HCHO} \\
\mathrm{HO}_{2}+\mathrm{NO} \rightarrow \mathrm{OH}+\mathrm{NO}_{2}
\end{gathered}
$$

Methyl nitrite was introduced into the chamber by filling a clean, evacuated, $500 \mathrm{~mL}$ glass bulb with the desired pressure of the standard, backfilling with $\mathrm{N}_{2}$, and transferring the contents of the bulb into the chamber with a stream of $\mathrm{N}_{2}$. In high$\mathrm{NO}_{2}$ experiments, the added $\mathrm{NO}_{2}$ and that formed from $\mathrm{CH}_{3} \mathrm{ONO}$ photochemistry conspire to maintain the $\mathrm{NO}_{2} / \mathrm{NO}$ ratio $>10$ throughout the experiment. Importantly, the near-UV broadband radiation used in this work does not efficiently photolyze $\mathrm{NO}_{3}$ via mechanisms that yield a net destruction of $\mathrm{NO}_{3}\left(J_{\mathrm{NO}_{2}} \sim 5.5 \times\right.$ $\left.10^{-4} \mathrm{~s}^{-1}, J_{\mathrm{NO}_{3}} \rightarrow{ }_{\mathrm{NO}+\mathrm{O}_{2}} \sim 4.5 \times 10^{-6} \mathrm{~s}^{-1}\right) .{ }^{24}$

\section{Analytical measurements}

MACR and isobutyraldehyde were quantified with a commercial gas chromatograph with a flame-ionization detector (GC-FID, HP $6890 \mathrm{~N}$ ) and calibrated by volumetric injections of commercial standards. Particle size and number were measured by a scanning mobility particle sizer (SMPS), i.e., a custom-built differential mobility analyser coupled to a commercial condensation particle counter (TSI Inc.). Aerosol speciation was measured using a high resolution time-of-flight aerosol mass spectrometer (AMS, Aerodyne). ${ }^{25}$ Bulk aerosol species (organic, sulfate, ammonium, nitrate) were calculated using AMS data analysis modules (Pika 1.14D). The instrument's ionization efficiency was calibrated with $350 \mathrm{~nm}$ ammonium nitrate particles.

Volatile acids and select polar organic compounds were quantified with a custom-built triple-quadrupole chemical ionization mass spectrometer (CIMS, Agilent/Caltech). ${ }^{26}$ The CIMS operated in three modes: scanning negative ion mode using $\mathrm{CF}_{3} \mathrm{O}^{-}$as the reagent $(\mathrm{m} / \mathrm{z} 50-250)$, scanning positive ion mode using primarily $\mathrm{H}_{3} \mathrm{O}^{+}$as the reagent ion $(\mathrm{m} / \mathrm{z} 50-200)$, and tandem mass negative ion mode (monitoring select precursorproduct ion pairs). The ion chemistry (e.g., detection as $[\mathrm{M}+\mathrm{F}]^{-}$ and $\left[\mathrm{M}+\mathrm{CF}_{3} \mathrm{O}\right]^{-}$ions $)^{27}$ and tandem mass determinations ${ }^{26}$ of the $\mathrm{CF}_{3} \mathrm{O}^{-}$CIMS have been described previously.

Sensitivities of the triple-quadrupole $\mathrm{CF}_{3} \mathrm{O}^{-}$CIMS used in this work were determined based on a calibrated time-offlight $\mathrm{CF}_{3} \mathrm{O}^{-}$CIMS instrument during the FIXCIT campaign. ${ }^{22}$ The absolute calibration for commercially-available and synthesized standards in the time-of-flight CIMS, using gravimetric, optical, and thermal-dissociation + laser-induced fluorescence methods are described elsewhere. ${ }^{28}$ Uncertainty is estimated to be $\pm 30 \%$. Synthesized standards of organic nitrates were found to have water-dependent sensitivities similar to $\mathrm{HNO}_{3} ;^{29}$ thus the CIMS sensitivity of the pinene nitrooxyhydroperoxide (PNP), for which there are no authentic standards, is assumed to be similar to $\mathrm{HNO}_{3}$ (estimated uncertainty $\pm 50 \%$ ). For other compounds discussed in this work, theoretical calculations ${ }^{30,31}$ were used to estimate the sensitivity (estimated uncertainty $\pm 50 \%)$.

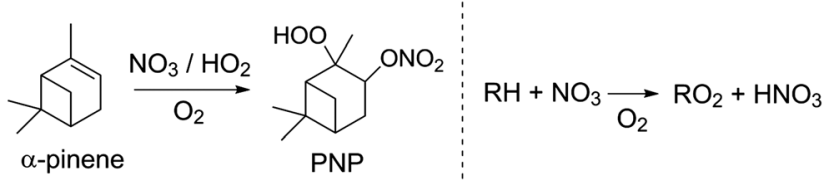

Fig. 3 The experimental scavenging of $\mathrm{NO}_{3}$ into stable products detectable by CIMS: PNP (one of several isomers shown) and $\mathrm{HNO}_{3}$.

The observed ion of methacrylic acid epoxide (MAE, synthesized standard, detected as $\left.[\mathrm{MAE} \cdot \mathrm{F}]^{-}\right)^{18}$ was isobaric with a water cluster $\left[\left(\mathrm{H}_{2} \mathrm{O}\right)_{2} \cdot \mathrm{CF}_{3} \mathrm{O}\right]^{-}(\mathrm{m} / z \mathrm{z} 121)$ in the single-ion analysis. Thus, MAE quantification is performed with collision-induced dissociation into its main precursor $\rightarrow$ product ion $(\mathrm{m} / z 121 \rightarrow$ $m / z$ 101). When experiments are performed at higher relative humidity, the water signal $(m / z 121 \rightarrow m / z 103)$ may have an extensive tail that would lead to an over-estimation of MAE. The tandem signal that we measure must then be considered as an upper limit to the MAE concentration. The ion chemistry in the positive ion mode is similar to proton transfer reaction ${ }^{32}$ mass spectrometry (quantification mainly with $[\mathrm{M}+\mathrm{H}]^{+}$ions in this work). Calibrations for select species in the positive ion mode (e.g., $\alpha$-pinene and 231MBO) were performed immediately prior to experiments using commercial standards under dry conditions.

CIMS was also used to indirectly monitor nitrogen oxide chemistry (Fig. 3). For example, the reaction of $\mathrm{NO}_{2}$ with $\mathrm{HO}_{2}$ generates peroxynitric acid $\left(\mathrm{HO}_{2} \mathrm{NO}_{2}, \mathrm{PNA}\right)$, which was used as a sensitive tracer for $\mathrm{NO}_{2} . \alpha$-pinene was used in a subset of experiments to capture $\mathrm{NO}_{3}$ as the pinene nitrooxy hydroperoxide (PNP), which is detectable by CIMS, under the condition where the $\mathrm{HO}_{2} / \mathrm{NO}$ ratio is high (Fig. 3, left). $\alpha$-pinene was chosen as an $\mathrm{NO}_{3}$ scavenger because its reaction rate coefficient with $\mathrm{OH}$ is the lowest for a monoterpene that reacts rapidly with $\mathrm{NO}_{3}$ (i.e., $k_{\mathrm{NO}_{3}} / k_{\mathrm{OH}} \sim 0.12$ ), ${ }^{33}$ and its reaction rate with $\mathrm{NO}_{3}$ is at least 4 orders of magnitude larger than the MPAN reaction with $\mathrm{NO}_{3} \cdot{ }^{34}$ There are varying reports of SOA yield from the $\alpha$-pinene $+\mathrm{NO}_{3}$ reaction $(0-16 \%),{ }^{35-37}$ possibly decreasing with higher RH. ${ }^{37}$ Thus, experiments involving $\alpha$-pinene were not included in the yield calculations from MPAN due to the possibility of interference from the $\alpha$-pinene $+\mathrm{OH}$ or $+\mathrm{NO}_{3}$ reaction. $\mathrm{HNO}_{3}$, produced from $\mathrm{H}$-abstraction chemistry of hydrocarbons (Fig. 3, right) when $\mathrm{NO}_{2}$ is low (and thus $\mathrm{NO}_{2}+\mathrm{OH}$ is not a significant source of $\mathrm{HNO}_{3}$ ), was also used as tracer for $\mathrm{NO}_{3}$-initiated chemistry.

MPAN, peroxyacetyl nitrate (PAN), and $\mathrm{NO}_{2}$ are measured with a commercial $\mathrm{NO}_{2}$ and acyl peroxynitrate $\left(\mathrm{NO}_{2} / \mathrm{APN}\right)$ analyser (Fitz Aerometric Technologies). In the $\mathrm{NO}_{2} / \mathrm{APN}$ instrument, $\mathrm{NO}_{2}$, PAN, and MPAN were chromatographically separated, in that order, with a room-temperature deactivated DB-5 column and detected by monitoring chemiluminescence from their reactions with luminol (Fig. $\mathrm{S} 1, \mathrm{ESI}^{\dagger}$ ). $\mathrm{NO}_{2}$ was calibrated with a diluted standard mixture (488 ppmv $\mathrm{NO}_{2}$ in $\mathrm{N}_{2}$, Scott Specialty Gases). The sensitivity of PAN in the instrument was inferred from its relationship to $\mathrm{NO}_{2} \cdot{ }^{38} \mathrm{MPAN}$, in isolation, was calibrated using a commercial $\mathrm{NO}_{x}$ analyser (Teledyne model T200) due to its quantitative decomposition to $\mathrm{NO}_{2}$ when 
exposed to the heated $\left(310^{\circ} \mathrm{C}\right)$ molybdenum catalyst. A similar calibration was obtained by thermally decomposing MPAN to $\mathrm{NO}_{2}$ in a heated stainless steel tube before the $\mathrm{NO}_{2} / \mathrm{APN}$ analyser. Sampling MPAN from the chamber (before adding other compounds) through room-temperature teflon tubing leads to a small decomposition yield of $\mathrm{NO}_{2}$ from MPAN ( $\sim 4 \%$, Fig. $\mathrm{S} 1, \mathrm{ESI} \dagger)$. The $\mathrm{NO}_{2}$ signal was corrected in the $\mathrm{NO}_{2} /$ APN data as a fraction of the MPAN integrated peak.

\section{MPAN}

The synthesis of MPAN from the peroxidation of methacrylic anhydride (Aldrich, 94\%) and nitration of the methacrylic peracid (MPAA) was performed as suggested by Bertman and Roberts $^{39}$ with the following revisions: we used $50 \mathrm{wt} \% \mathrm{H}_{2} \mathrm{O}_{2}$ (Aldrich) instead of $30 \mathrm{wt} \% \mathrm{H}_{2} \mathrm{O}_{2}$ and methanesulfonic acid (Aldrich, 99.5\%) instead of conc. $\mathrm{H}_{2} \mathrm{SO}_{4}$. The crude MPAN mixture in water-tridecane was stored frozen and separated in small fractions with tridecane on a silica gel column deactivated by successive solvent washes of methanol, acetone, ethyl acetate, hexanes, and tridecane. Signs of known impurities were checked by CIMS (i.e., methacrylic acid and MPAA) and the $\mathrm{NO}_{2} / \mathrm{APN}$ instrument (PAN). MPAN is thought to be explosive when pure ${ }^{40}$ and no attempt was made to remove the solvent. The separated MPAN fraction in tridecane was stored at $0{ }^{\circ} \mathrm{C}$ or below and used promptly.

MPAN was injected by gently bubbling air through the tridecane-solvated mixture (submerged in an ice bath) placed inside the $15{ }^{\circ} \mathrm{C}$ chamber enclosure over the course of roughly $30 \mathrm{~min}$ to achieve $15-30 \mathrm{ppbv}$ in the chamber. Tridecane was chosen as the storage solvent due to its low volatility, and thus, lower extent of co-evaporation into the chamber. To correct for any SOA originating from photooxidation of the solvent, we performed a control photooxidation experiment with tridecane $+\mathrm{OH}$ similarly to Exp. 2-3. The CIMS signals of tridecane (positive mode) and tridecane hydroperoxide (negative mode) were used to normalize the $10-50 \%$ correction of tridecanederived SOA in MPAN experiments.

\section{MGA}

2-Methylglyceric acid (2MGA) was synthesized and purified according to An et al. ${ }^{41}$ via oxidation of the $\mathrm{C}=\mathrm{C}$ bond of methacrylic acid (Aldrich, 99\%) using $\mathrm{H}_{2} \mathrm{WO}_{4}$ (Aldrich, 99\%) and $50 \mathrm{wt} \% \mathrm{H}_{2} \mathrm{O}_{2}$ (Aldrich). Proton NMR (in DMSO- $\mathrm{d}_{6}$ ) was used to verify the isolated 2MGA with residual $\mathrm{CH}_{3} \mathrm{CN}(93 \%$ 2MGA, Fig. S2A, ESI $\dagger$ ). The semi-pure 2MGA (viscous liquid) was then crystallized upon cooling, filtered with $\mathrm{CH}_{3} \mathrm{CN}$, and washed with $\mathrm{Et}_{2} \mathrm{O}$ to afford the pure (99\%) 2MGA crystalline solid. The CIMS observes 2MGA at the fluoride transfer ion $\left(\mathrm{C}_{4} \mathrm{H}_{7} \mathrm{O}_{4} \cdot \mathrm{HF}^{-}\right)$and collision-induced dissociation leads primarily to the deprotonated 2MGA ion $\left(\mathrm{C}_{4} \mathrm{H}_{7} \mathrm{O}_{4}{ }^{-}\right.$, Fig. S2B, ESI $\left.\dagger\right)$. The gas-phase signal of a $2 \mathrm{MGA}$ aqueous solution was measured at various solution $\mathrm{pH}$ values in a custom $10 \mathrm{~mL}$ glass vial fitted with $3 \mathrm{~mm}$ O.D. PTFE sampling tubes. A $0.075 \mathrm{M}$ solution of 2MGA had similar $\mathrm{pH}$ to glyceric acid $\left(\mathrm{p} K_{\mathrm{a}} 3.5\right)^{42}$ at the same concentration. The 2MGA solution was further acidified incrementally by adding droplets of 1-10 wt $\% \mathrm{H}_{2} \mathrm{SO}_{4}$ and the $\mathrm{pH}$ of the solution was measured with a digital pH meter (VWR, Model 8015 ) that had been calibrated with commercial buffer solutions. The headspace of the vial (at $24{ }^{\circ} \mathrm{C}$ ) was sampled with CIMS at a flow rate of $147 \mathrm{std}^{3} \mathrm{~s}^{-1}$ for each solution $\mathrm{pH}$.

\section{High-resolution mass spectrometry}

At the end of photooxidation experiments, SOA samples were collected on hydrophilic PTFE-based membrane filters (Millipore, Omnipore, $0.2 \mu \mathrm{m}$ diameter pores) by pulling chamber air through an activated charcoal denuder, vacuum-sealed, and frozen for further analysis. The SOA material on the filters was gently extracted by wetting with $100-300 \mu \mathrm{L}$ of acetonitrile and water mixture (2:5 v/v, HPLC grades) for roughly $5 \mathrm{~min}$. The filters were not exposed to heat or ultra-sonication conditions (which may produce free radicals such as $\mathrm{OH}$ through cavitation $)^{43}$ in order to preserve organic species. The extracts were analysed with high-performance liquid chromatography (HPLC) coupled to electrospray ionization mass spectrometry (ESIMS). The separation was performed with a polar embedded $\mathrm{C}_{18}$ column with TMS endcapping (Phenomenex, Synergi ${ }^{\mathrm{TM}}$ $4 \mu \mathrm{m}$ Fusion-RP $80 \AA$ A, $150 \times 2.0 \mathrm{~mm}$ ) and an eluent mixture of acetonitrile and water (HPLC grades, Aldrich) with $0.5 \%$ of formic acid. Generally, the organic constituents eluted together (e.g., the entire oligomer family of 2-methylglyceric acid in the $\mathrm{MPAN}+\mathrm{OH}$ samples) but are satisfactorily separated from the inorganics. Additionally, an ammonium sulfate solution was analysed with HPLC-ESIMS as an inorganic blank. $\mathrm{HSO}_{4}{ }^{-}$, $\mathrm{HSO}_{4}\left(\mathrm{H}_{2} \mathrm{SO}_{4}\right)^{-}$, and $\mathrm{HSO}_{4}\left(\mathrm{H}_{2} \mathrm{SO}_{4}\right)_{2}{ }^{-}$were the dominant ions observed from the ammonium sulfate solution. These ion signals were subtracted from the SOA mass spectra to remove the remaining inorganic contribution. The mass analyser was a high-resolution (100000 $\mathrm{m} / \Delta \mathrm{m}$ at $\mathrm{m} / \mathrm{z}$ 300) linear-ion-trap (LTQ) Orbitrap $^{\mathrm{TM}}$ mass spectrometer (Thermo Corp.) operated in the negative ion mode with a mass range of $80-2000 \mathrm{~m} / \mathrm{z}$. The LTQOrbitrap was calibrated with commercial standard (LTQ ESI Negative Ion Calibration Solution, Thermo Scientific, Inc.) prior to mass spectral analyses (mass accuracy up to $0.5 \mathrm{ppm}$ at $\mathrm{m} / \mathrm{z} 500$ ).

\section{Results and discussion}

\section{Photooxidation of MPAN}

Fig. 4A shows the reaction progress for a representative low-NO MPAN experiment under dry conditions. Reagents were equilibrated in the chamber prior to the initiation of photochemistry (yellow shaded region). Fig. 4B shows a representative low-NO MPAN experiment where $\alpha$-pinene was added at the beginning of the reaction to scavenge $\mathrm{NO}_{3}$, and MAE was added at the end (after the reaction mixture has stabilized with lights off) to observe its effects on SOA formation.

A low yield of $\mathrm{NO}_{2}(7 \pm 3 \%)$ is observed by the $\mathrm{NO}_{2} / \mathrm{APN}$ instrument and confirmed by the negligible CIMS PNA signal. This $\mathrm{NO}_{2}$ formation is likely due to thermal decomposition of MPAN $\left(\tau_{288 \mathrm{~K}} \sim 35 \mathrm{~h} \text { at the } \mathrm{NO}_{x} \text { conditions in Exp. } 2-3\right)^{23,44}$ because a $10 \pm 5 \%$ yield of PAN was also observed. The MPAN decomposition produces $\mathrm{NO}_{2}$ and acylperoxyl radical, which is 

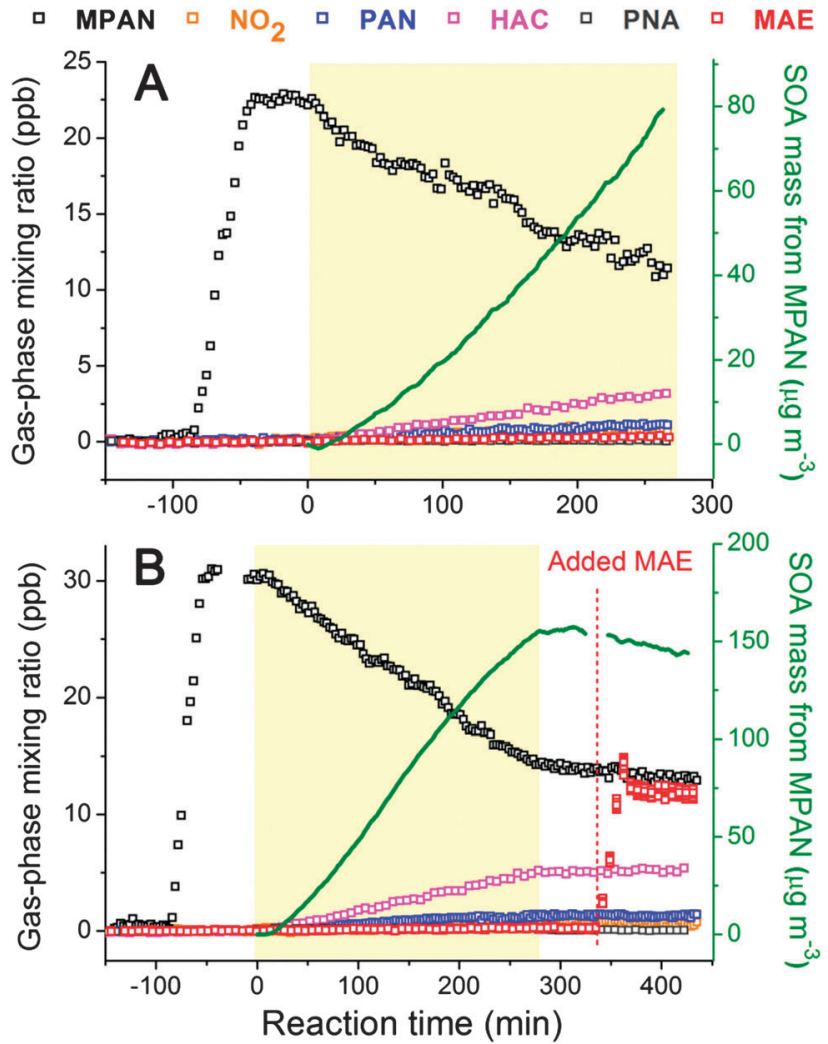

Fig. 4 Representative MPAN photooxidation experiments (A) performed with MPAN and $\mathrm{H}_{2} \mathrm{O}_{2}$ (Exp. 3, base experiment) and (B) the base experiment with the initial addition of $\alpha$-pinene and subsequent injection of MAE standard (Exp. 4). The yellow shaded areas designate the time period when photochemistry occurs in each experiment. The right mass axis corresponds only to the SOA trace (green line).

subsequently converted to the acyloxyl radical from reaction with either $\mathrm{NO}$ or $\mathrm{HO}_{2}{ }^{8}$ The acyloxyl radical decarboxylates to the vinyl radical that ultimately forms PAN and other products through subsequent reactions. ${ }^{45}$ The thermal decomposition is calculated to be $10-25 \%$ of the total MPAN loss, qualitatively consistent with observed yields. The uncertainty is due to difficulty in determining the $\mathrm{NO}_{2} / \mathrm{NO}$ ratio when $\mathrm{NO}_{x}$ is low. Neither PAN nor the $\mathrm{NO}_{2}$ yield was enhanced in the presence of $\alpha$-pinene (Fig. 4B), suggesting they both originate from MPAN. The lower bound $(10 \%)$ of the MPAN decomposition is used to correct gaseous molar yields.

In contrast to $\mathrm{NO}_{2}$, the experiments performed with $\alpha$-pinene conclusively demonstrate high yields of an $\mathrm{NO}_{3}$ co-product, as suggested by mechanisms 1 and 3 (Fig. 2). Fig. 5 shows that upon photooxidation of MPAN in the presence of $\alpha$-pinene, PNP is formed in $\sim 35 \pm 17 \%$ yields with respect to $\alpha$-pinene loss and $\sim 70 \pm 35 \%$ yield with respect MPAN loss. Experiments without $\alpha$-pinene did not produce interfering species at the mass used for quantification of PNP. Furthermore, experiments performed during the FIXCIT campaign (Exp. \# 10, 13 in Table 2 of that work $)^{22}$ with 30 ppbv of $\alpha$-pinene demonstrate that PNP is not formed under low-NO photooxidation conditions, similar to those used to oxidize MPAN here (Fig. S3a, ESI $\dagger$ ). However, PNP is an abundant product when $\mathrm{NO}_{3}$ is used as an oxidant

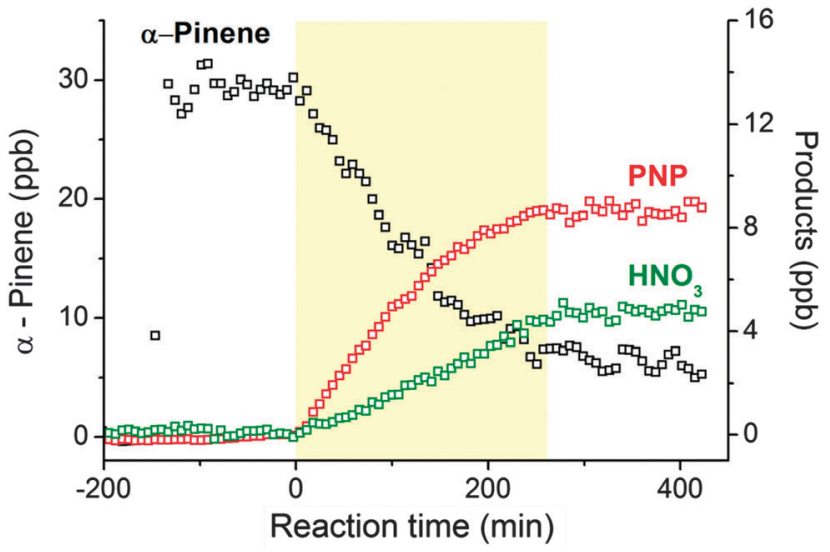

Fig. 5 Representative result from $\mathrm{NO}_{3}$ scavenging experiment using $\alpha$-pinene (Exp. 4). The yellow shaded area designates the time period when photochemistry occurs. Note the double-vertical scales.

while $\mathrm{HO}_{2}$ is present in the chamber (Fig. S3b, ESI $\dagger$ ). Using known rate coefficients of $\alpha$-pinene with $\mathrm{NO}_{3}$ and $\mathrm{OH},{ }^{33}$ we estimate the steady state $\mathrm{NO}_{3}$ concentration in Exp. 4 (Table 1) to be $6.5 \times 10^{6} \mathrm{~mol} \mathrm{~cm}^{-3}$. The steady state $\mathrm{OH}$ concentration $\left(\sim 1.5 \times 10^{6} \mathrm{~mol} \mathrm{~cm}^{-3}\right)$, which is reproducible within $25 \%$ under identical oxidant precursor and light conditions, ${ }^{22}$ is derived from separate low-NO photolysis experiments using isoprene as a reference hydrocarbon. Thus, we estimate that the loss of $\alpha$-pinene is $\sim 40 \%$ by $\mathrm{NO}_{3}$ and $\sim 60 \%$ by $\mathrm{OH}$. This is in relatively good agreement with the PNP yield from $\alpha$-pinene assuming most of the pinene nitrooxy alkylperoxyl radical reacts with $\mathrm{HO}_{2}$ to form PNP.

$\mathrm{HNO}_{3}$ formation in MPAN experiments (Fig. 5) occurs likely from the $\mathrm{NO}_{3}$-initiated $\mathrm{H}$-abstraction of alkanes (e.g., tridecane from the introduction of MPAN) or other saturated compounds, as the reaction of $\mathrm{NO}_{3}$ with $\alpha$-pinene and MPAN will result largely in addition rather than abstraction. Using the steadystate radical concentrations derived above and reaction rate coefficients from the literature, ${ }^{34}$ we estimate $<0.1 \%$ of the MPAN loss was due to reaction with $\mathrm{NO}_{3}$ radicals. $\mathrm{HNO}_{3}$ is observed in all MPAN photooxidation experiments due to the ubiquitous presence of the tridecane solvent, and no enhancement is observed in the presence of $\alpha$-pinene. $\mathrm{HNO}_{3}$ provides evidence of another $30 \pm 9 \% \mathrm{NO}_{3}$ yield from MPAN, which taken together with PNP, suggests that MPAN efficiently yields $\mathrm{NO}_{3}$ and a co-product upon reaction with $\mathrm{OH}$. The high $\mathrm{NO}_{3}$ yield confirms one shared aspect of mechanisms 1 and 3 (Fig. 2) and, in combination with the low $\mathrm{NO}_{2}$ observations, allows us to rule out mechanism 2 as a significant contributor to the MPAN photooxidation chemistry.

We observe a large mass yield of SOA from the dry MPAN + $\mathrm{OH}$ experiments (Fig. 4, green traces), suggesting that the MPAN photooxidation chemistry is efficient at forming SOA in the absence of $\mathrm{NO}_{x}$. Approximately $125-145 \%$ SOA by mass (with respect to MPAN mass reacted) is formed, and assuming an average molecular weight of $340 \mathrm{~g} \mathrm{~mol}^{-1}$ (the intensityweighted average of the MPAN $+\mathrm{OH}$ high-resolution mass spectrometry data, assuming similar ESIMS sensitivities for 
observed analytes), approximately $\sim 60(+15 /-5) \%$ by mole. The uncertainty is derived from corrections (e.g., for tridecanederived SOA, particle wall loss, and MPAN thermal decomposition) and analysis of the average molecular weight of the SOA. The observation that SOA formation from MPAN $+\mathrm{OH}$ is not NO-dependent is consistent with the suggestion in mechanisms 1 and 3 (Fig. 2) that the traditional $\mathrm{RO}_{2}$ chemistry of the thermalized radical A does not come into play. However, we note the data do not eliminate the possibility that an $\mathrm{RO}_{2}$ formed after $\mathrm{O}_{2}$ addition also rapidly decomposes to the same products.

Importantly, the SOA formation from MPAN $+\mathrm{OH}$ is prompt and occurs without the injection of inorganic seed aerosols. It is possible the SOA forms via nucleation (e.g., from the chemistry of larger VOC like tridecane) or growth in the presence of pre-existing seed particles that are under the size detection limit of the SMPS and AMS. Even if SOA growth occurs on dry, pre-existing, nanoparticles, most of the SOA formation occurs on primarily-organic particles after the first few condensation cycles. This observation favors the proposed mechanism 3 over mechanism 1 due to the need for MAE to undergo reactive uptake partitioning, which is a slow process for this compound even in the presence of hydrated, acidic sulfate particles that would accelerate ring-opening of the epoxide $\left(\gamma \sim 5 \times 10^{-4}\right.$ when seed aerosols are $50 \% \mathrm{H}_{2} \mathrm{SO}_{4}$ by mass). ${ }^{46}$

Of the putative SOA precursors, MAE is the only compound that has been detected by mass spectrometry due to its chemical stability. Throughout all experiments, we observed small to negligible yields of MAE in the gas phase $(2 \pm 1 \%$, upper limit, see Experimental), whether the precursor was MPAN or MACR. FIXCIT experiments of MACR under low-NO conditions also did not observe any appreciable MAE production. ${ }^{22}$ Lin et al. ${ }^{18}$ similarly observed a small gas-phase yield of MAE ( 1\% from MACR, Fig. S1 of that work), but suggested that MAE is so rapidly converted to SOA mass that most of it is observed in the condensed phase. Under the assumption that $50-80 \%$ of MAE is observed as SOA, they estimated MAE yields are $18-32 \%$ from MPAN. We demonstrate that MAE is not wellconverted to SOA and, in particular, not via the mechanism that forms the dominantly-organic particles in the MPAN experiments. It instead appears that MAE is a remarkably stable and volatile gas-phase species, with similar volatility to MPAN, which by itself does not form SOA through equilibrium partitioning. Notably, when $\sim 12( \pm 50 \%)$ ppbv of MAE is injected into the chamber following the reaction period (Fig. 4B), no change to particle size or mass concentration can be observed.

To further evaluate the inertness of MAE, we injected a few hundred ppbv of MAE into a clean $1000 \mathrm{~L}$ teflon bag alongside 500 ppbv of $\mathrm{HNO}_{3}(\sim 300$ ppbv of which remained in the gas phase, and the rest, presumably, coated the chamber walls). No observable wall loss of MAE occurred over the course of 2.5 hours (Fig. S4, ESI $\dagger$ ); this is identical to its behavior in the absence of acid. It appears that the small quantity of MAE formed from MACR oxidation is not an eager participant in the surface- and/or water-induced partitioning that often leads to SOA formation. The inertness we observe provides insight into why $300 \mathrm{ppbv}\left(\sim 1250 \mu \mathrm{g} \mathrm{m}^{-3}\right)$ of MAE produced only $\sim 10 \mu \mathrm{g} \mathrm{m}^{-3}$ of SOA through reactive uptake in the Lin et al. ${ }^{18}$ work, even when using seed particles that are exceptionally acidic $\left(\sim 50 \mathrm{wt} \% \mathrm{H}_{2} \mathrm{SO}_{4}\right.$ at $\mathrm{RH}<10 \%)$. The evidence suggests that the low $(<2 \%)$ gasphase mixing ratios observed in this work and by Lin et al. ${ }^{18}$ (from MACR) indeed represent a measure of the entire yield of MAE. Thus, it appears that the disagreement between this work and that of Lin et al. ${ }^{18}$ lies in the assumption of MAE's ability to form SOA, and not in the observations of MAE itself. As MAE formation is negligible both from MPAN and MACR, mechanism 1 is ruled out as a significant contributor to MPAN-derived SOA.

A key element to understanding the MPAN $+\mathrm{OH}$ reaction lies in the measurement of hydroxyacetone (HAC). The HAC yield determined here $(\sim 25 \pm 7 \%)$ is consistent with the upper limit determined by Orlando et al. $(<40 \%),{ }^{21}$ but more than a factor of two lower than the yield determined by Grosjean et al. $(\sim 60 \%) .{ }^{20}$ Both of the previous works were performed under high-NO conditions using ethyl nitrite as an $\mathrm{OH}$ precursor. The source of discrepancy with regards to the Grosjean work is not clear; however, a similar trend in data agreement can be observed in the determination of rate coefficients of $\mathrm{OH}+$ MPAN. We measured $k_{288 \mathrm{~K}} \sim 3( \pm 1) \times 10^{-11} \mathrm{~cm}^{3} \mathrm{~mol}^{-1} \mathrm{~s}^{-1}$, which compares well with Orlando et al. ${ }^{21}\left(k_{277 \mathrm{~K}} \sim 3.2( \pm 0.8) \times\right.$ $10^{-11} \mathrm{~cm}^{3} \mathrm{~mol}^{-1} \mathrm{~s}^{-1}$ ), but is an order of magnitude higher than the value reported by Grosjean et $a l^{20}\left(k_{298 \mathrm{~K}} \sim 3.6( \pm 0.4) \times\right.$ $\left.10^{-12} \mathrm{~cm}^{3} \mathrm{~mol}^{-1} \mathrm{~s}^{-1}\right)$. The coefficient by Orlando et al. is preferred by IUPAC $^{33}$ due to its consistency with the $\mathrm{OH}$ reaction with structurally-similar APNs, ${ }^{47}$ and our data is in agreement with this recommendation. Thus, we only consider the comparison between this work and that of Orlando et al. ${ }^{21}$

If the production of HAC occurs via the lactone-production pathway (as the data seem to indicate) then the yield would be independent of NO mixing ratio. The agreement in the HAC yield obtained under low-NO conditions (this work) and high-NO conditions ${ }^{21}$ suggests that HAC is not formed from the alkylperoxyl radical $\mathrm{B}$ in the MPAN $+\mathrm{OH}$ reaction. Finally, the experimentally-determined HAC yield (and, consequently the remainder HMML yield) is comparable to those theoretically predicted by Kjaergaard et al. ${ }^{17}$ ( $\sim 36 \%$ of HAC). In contrast, Lin et al. ${ }^{18}$ suggest a low HAC yield $(\sim 3 \%)$. The current work cannot differentiate the $2 \%$ of thermalized radical A that is predicted to form, ${ }^{17}$ ultimately generating the alkoxyl radical under high $\mathrm{NO}_{x}$ conditions, because the products would likely include HAC and $\mathrm{NO}_{3}$. Together, the experimental data support the HMML mechanism from the MPAN $+\mathrm{OH}$ reaction. We estimate approximately $25 \%$ of the reaction yields $\mathrm{HAC}+\mathrm{CO}+\mathrm{NO}_{3}$ and $75 \%$ of the reaction yields $\mathrm{HMML}+\mathrm{NO}_{3}$, with $75-100 \%$ of $\mathrm{HMML}$ leading to the formation of SOA under dry conditions.

To investigate whether there is a route to HMML from thermalized alkyl radicals, we performed experiments with saturated APNs that are analogous to MPAN. The photooxidation of the saturated analogues occurs via $\mathrm{H}$-abstraction instead of $\mathrm{OH}$-addition, which generates lower-energy alkyl radicals. For example, we synthesized A in the chamber via the $\mathrm{OH}$-initiated photochemistry of 3-hydroxy-2-methylpropanoyl peroxynitrate (HMPPN). HMPPN is a major product of the high- $\mathrm{NO}_{2} \mathrm{OH}$-initiated oxidation 
of hydroxymethyl propanal (HMP), which was produced by dark ozonolysis of 231MBO (Section S1 and Fig. S5 and S6A, ESI $\dagger$ ). Expected gas-phase products arising from $\mathrm{RO}_{2}$ and $\mathrm{RO}$ radicals were observed from the chemistry of A but not $A^{*}$ (Fig. S7, ESI $\dagger$ ), e.g., the hydroxynitrate, the hydroxyhydroperoxide, hydroxyacetone, and 2-oxopropanoyl peroxynitrate. ${ }^{21}$ Qualitatively compared to MACR, the SOA formation from the photochemistry of HMP (Exp. \#11, Fig. S6B, ESI $\dagger$ ) and isobutyraldehyde (Exp. \#10, not shown) is negligible ( $\ll 1 \%)$. Chan et al. ${ }^{13}$ first suggested the importance of the $\beta$-unsaturation in MPAN, following the observation that $\alpha, \beta$-unsaturated aldehydes produced the largest SOA yields. Our results are consistent with their explanation.

Additionally, we use the potential energy surfaces from the Kjaergaard et al. ${ }^{17}$ work to calculate the relative fates of A. Compared to a typical effective rate for the reaction of alkyl radicals with $\mathrm{O}_{2}$ at $1 \mathrm{~atm}$ air $\left(\mathrm{O}_{2}=21 \%\right)$ and $298 \mathrm{~K}\left(k_{\text {eff }} \sim 1 \times 10^{7} \mathrm{~s}^{-1}\right)$, the thermalized unimolecular decomposition of $\mathrm{A}$ to HMML is much slower $\left(k_{(\mathrm{A} \rightarrow \mathrm{HMML})}<10^{3} \mathrm{~s}^{-1}\right)$. This translates to a calculated $0 \%$ yield of HMML in the HMPPN + OH reaction $\left(100 \%\right.$ reacts with $\left.\mathrm{O}_{2}\right)$. In comparison, Kjaergaard et al. ${ }^{17}$ estimated the decomposition of $\mathrm{A}^{*}$ to HMML is fast under the conditions they studied $\left(k_{\left(\mathrm{A}^{*} \rightarrow \mathrm{HMML}\right)} \sim\right.$ $4 \times 10^{9} \mathrm{~s}^{-1}$ ), translating to a 61-74\% HMML yield from MPAN ( $2 \%$ is stabilized to A). The theoretical-derived kinetic results are consistent with observations for these $\mathrm{C}_{4} \mathrm{APN}$-derived alkyl radicals.

Fig. 6 summarizes the chemical mechanisms in the $\mathrm{OH}$-initiated oxidation of MPAN and HMPPN to reflect the current scientific knowledge. It is also possible that larger APNs behave differently than the $\mathrm{C}_{4}$ APNs discussed here. For example, it is not clear if APNs from the monoterpene aldehydes such as pinonaldehyde (saturated) and limonaldehyde (unsaturated, in the gamma position) are able to produce SOA or undergo a different photochemical fate. These larger APN systems are intriguing because they can be produced in the laboratory ${ }^{22}$ but have not been observed in the ambient atmosphere.

\section{Atmospheric fate of HMML}

To study the SOA formation from HMML under conditions more relevant to the atmosphere, we performed MACR high$\mathrm{NO}_{2}$ photooxidation experiments with hydrated ammonium sulfate (AS) seed particles at 40 and 85\% RH (efflorescence and deliquescence $\mathrm{RH}$ of $\mathrm{AS}$ are $\sim 30$ and $\sim 80 \%$, respectively). ${ }^{48}$ Fig. 7 shows that the SOA production is lower and gas-phase 2MGA yields are higher when the reaction occurs in deliquesced AS particles (Exp. \#13, liquid water 75 vol\%) compared to primarily organic particles (under dry conditions, Exp. \#9). The small MAE signal did not increase under humid conditions, suggesting that the formation of this compound is likely not important in the ambient environment. The production of HAC is observed to slightly increase toward the end of the experiment. However, this change is within the uncertainty of the HAC determination $( \pm 30 \%)$. If the difference in HAC signal between dry and humid is real, the underlying mechanism is unclear. The systematic uncertainty in calculating mixing ratio for $2 \mathrm{MGA}$ is approximately $\pm 50 \%$. However, if all of the $\sim 12-13 \mathrm{ppb}$ of $2 \mathrm{MGA}$ in the gas phase is converted to particle mass, the volatilization of 2 MGA may explain almost $100 \%$ of the $\sim 60 \mu \mathrm{g} \mathrm{m}^{-3}$ SOA mass discrepancy between the two experiments. 2MGA is typically used as a tracer for isoprene SOA; however, it appears that its accommodation in the condensed phase is low at typical aerosol-phase pH. Recent observations in the Southeast U.S. and Amazon forests support the idea that 2MGA may exist primarily in the gas phase in humid biogenic environments. ${ }^{49}$

Fig. 8A shows the CIMS gas-phase measurement of 2MGA (from a $0.075 \mathrm{M}$ solution of the synthesized standard) as the solution is increasingly acidified. 2MGA behaves similarly to a semivolatile compound such as isoprene epoxydiol in the CIMS instrument, i.e., it takes approximately 10 minutes to equilibrate

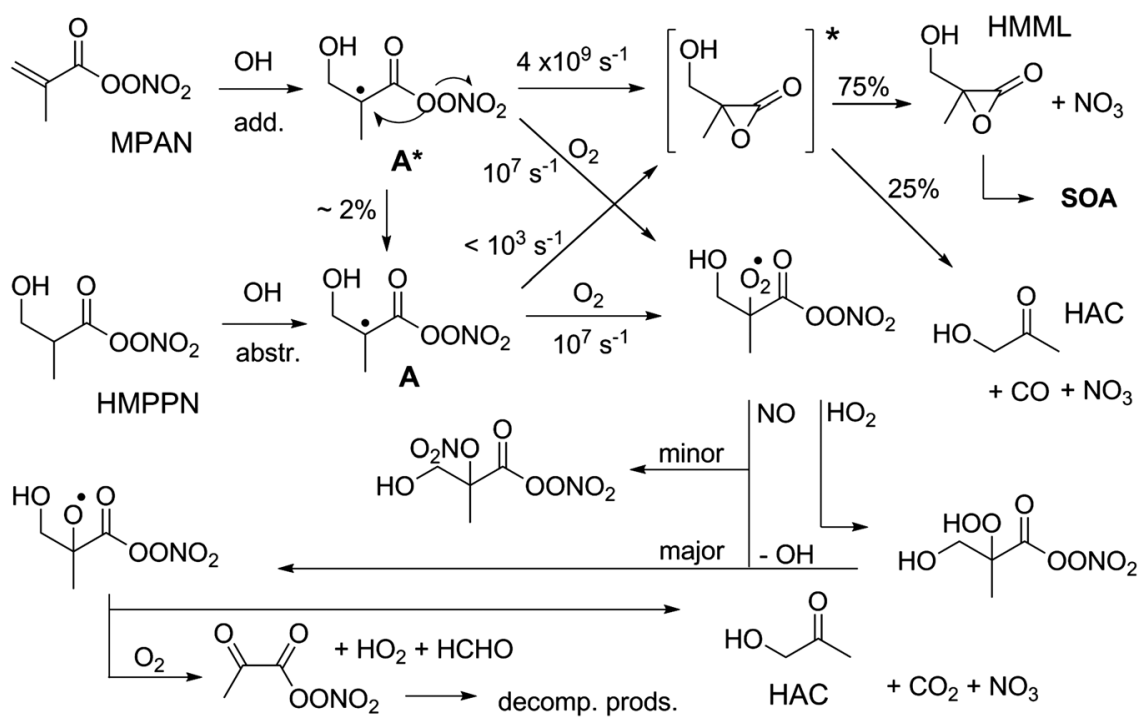

Fig. 6 The $\mathrm{OH}$-initiated oxidation mechanism of MPAN and HMPPN derived from the low-RH experiments conducted in this work. The HMML formation from MPAN arises from a chemically-activated mechanism while the product formation from HMPPN arises from a thermalized alkyl radical + $\mathrm{O}_{2}$ reaction. 


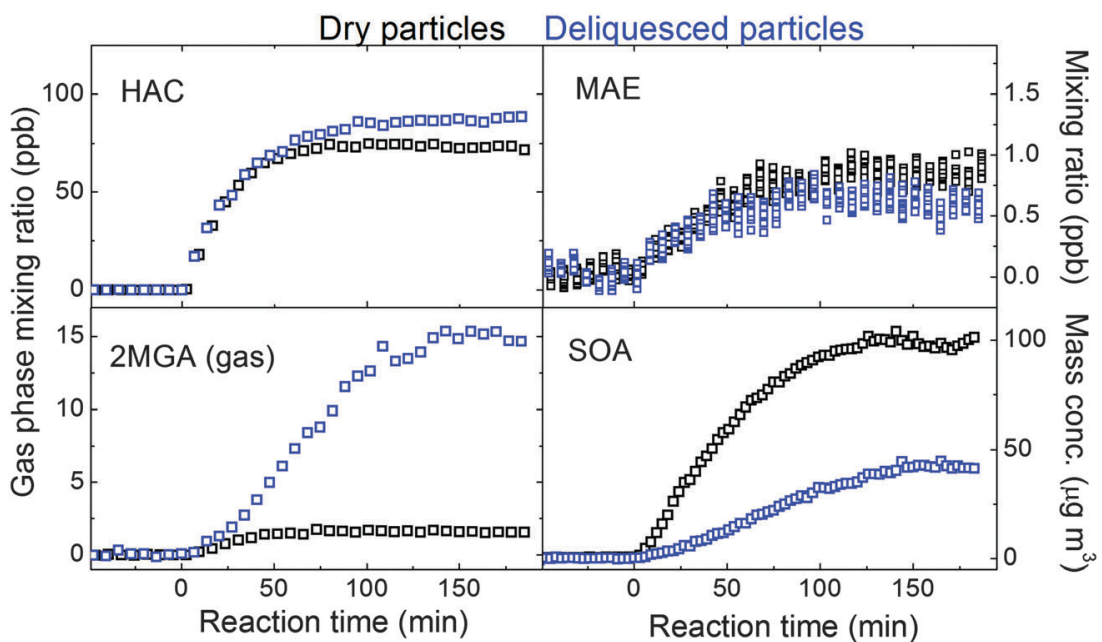

Fig. 7 The formation of gas-phase species and secondary organic aerosols under dry conditions (black markers) and under humid conditions (85\% RH) with deliquesced ammonium sulfate seeds (blue markers).

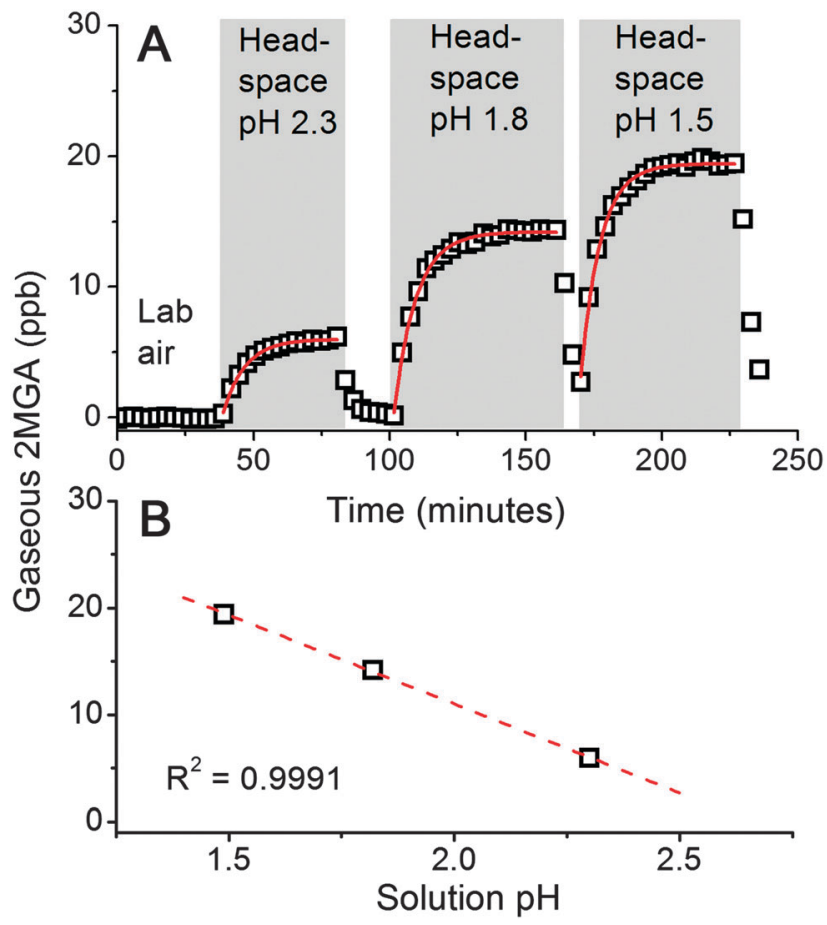

Fig. 8 CIMS measurements of the headspace air above a $0.075 \mathrm{M}$ 2-methylglyceric acid (2MGA) solution: (A) the gaseous 2MGA signal when switching from lab air to solutions with different $\mathrm{pH}$ and (B) the headspace 2MGA mixing ratio (obtained through exponential fitting) is a linear function of $\mathrm{pH}$ in the measurement range.

with teflon tubing compared to a more-volatile compound such as hydroxyacetone ( $<1 \mathrm{~min}$ ). The gas-phase mixing ratio linearly increases with decreasing solution pH (Fig. 8B) in the measurement range, as expected for a semi-volatile organic acid. This pH-dependent volatilization is likely to be important for understanding the SOA formation from not only MPAN oxidation, but other types of atmospheric reactions that produce organic acids in the condensed phase, e.g., cloud-processing oxidation, ${ }^{50,51}$ ozonolysis of alkenes, ${ }^{52,53}$ among other reactions.
Interestingly, gas-phase 2MGA is not significantly enhanced and aerosol mass is not significantly decreased in the $40 \% \mathrm{RH}$ experiment (Exp. \#12) compared to the dry experiments. It is possible that the liquid water content under these conditions $(\sim 30 \mathrm{vol} \%)$ is not high enough to dominate the reaction with

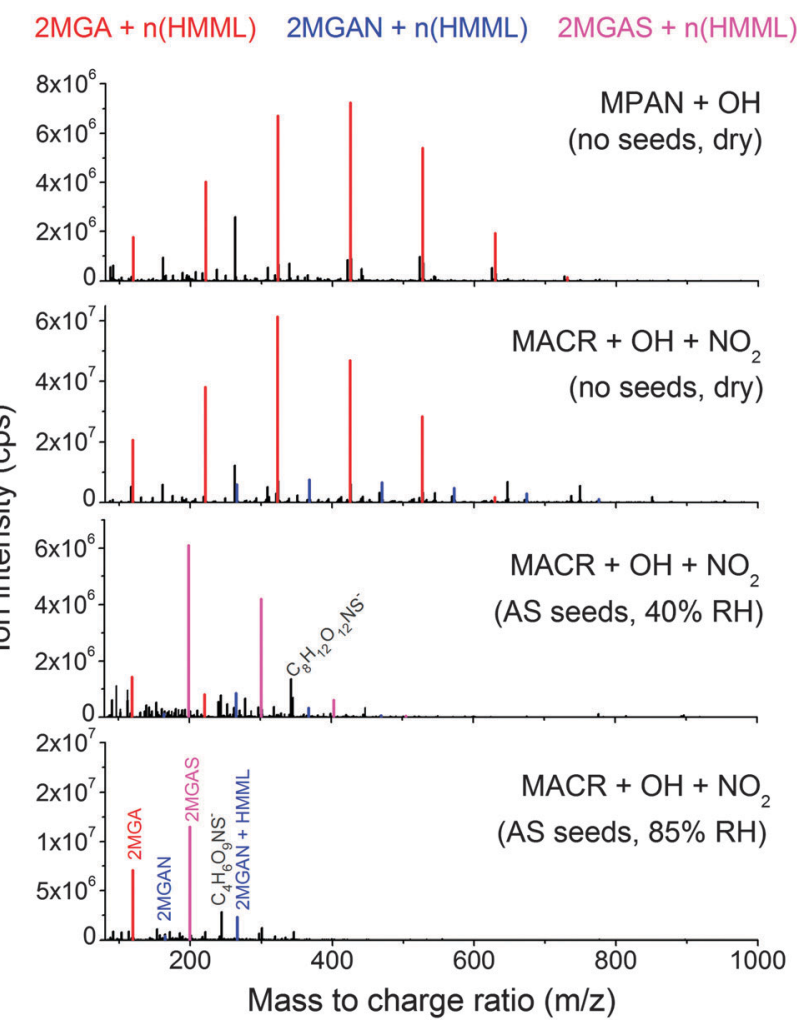

Fig. 9 Negative mode ESI-HRMS analysis of select SOA samples, integrated for retention times 2.5-3.5 min. The inorganic constituents have been separated by HPLC. Oligomer families comprised of HMML units are colorcoded based on the monomer compounds (2MGA $=2$-methylglyceric acid, $2 \mathrm{MGAN}=2$-methylglyceric acid nitrate, and $2 \mathrm{MGAS}=2$-methylglyceric acid sulfate). 
HMML or there is a barrier to 2MGA volatilization. For example, if organic-inorganic phase separation occurs at $\mathrm{RH}$ between efflorescence and deliquescence, ${ }^{54,55}$ the reaction of gas-phase HMML with water and solvated ions and the volatilization of aqueous 2MGA may be hindered by an organic shell. Additionally, when liquid water content is lower (and thus, ionic strength is higher), organic acids such as 2MGA may form involatile salts with $\mathrm{NH}_{4}{ }^{+}$and other cations. ${ }^{56}$ Salt formation is not expected to be significant for deliquesced particles, but can be considerably enhanced for drier metastable particles at $30-50 \%$ RH. ${ }^{57}$

Fig. 9 shows the results of high-resolution mass spectrometry (HR-MS) analyses of SOA collected from MPAN and MACR photooxidation. When the photooxidation of MACR is performed without inorganic seeds and under dry conditions, long oligomer families of 2MGA that are separated by $102.0317 \mathrm{Da}$ (the exact mass of HMML) are observed, consistent with earlier mass spectrometry observations. ${ }^{12,14,58}$ The SOA composition from MPAN + OH appears almost identical to that of MACR + $\mathrm{OH}+\mathrm{NO}_{2}$. In addition to the 2MGA + HMML oligomers, the MACR high- $\mathrm{NO}_{x}$ photooxidation produces an organic nitrogen oligomer family (Fig. 9, blue peaks). The organic nitrogen family of 2MGA-nitrate + HMML elutes primarily at later retention times (8-20 min), likely due to their lower polarity compared to organic sulfates and acids, but is absent in other chemical systems, including the MPAN + OH low- $\mathrm{NO}_{x}$ reaction. These $\mathrm{N}$-containing SOA compounds are likely formed from the reaction of $\mathrm{HNO}_{3}$ (from $\mathrm{NO}_{2}+\mathrm{OH}$ reaction in the MACR high- $\mathrm{NO}_{x}$ experiments) with HMML in the condensed phase or interfacial region, which generate the nitrate ester of 2MGA through nucleophilic ring opening.

When aqueous sulfate is present, the sulfate ester of 2MGA is produced (Fig. 9, magenta peaks), which react with HMML similarly to 2MGA and 2MGA-nitrate. In ammonium sulfate particles at $40 \% \mathrm{RH}$, the oligomer families of 2MGA-sulfate + $n$ (HMML) and 2MGA $+n$ (HMML) are observed up to the trimer and dimer, respectively. In the deliquesced AS seeds at $85 \% \mathrm{RH}$, the monomer compounds 2MGA, 2MGA-sulfate, and the sulfate nitrate $\left(\mathrm{C}_{4} \mathrm{H}_{6} \mathrm{O}_{9} \mathrm{NS}^{-}\right.$ion $)$dominate the mass spectra. An exception is the dimer 2MGA-nitrate + HMML that has higher signal than the monomer. This may be attributed to the fact that nitrate ion is a poor nucleophile and nucleophilic substitution with water and sulfate may readily occur, so the monomer nitrate has a short condensed-phase lifetime. Thus, the organonitrate may be more stable in the dimer form. However, it is also possible the nitrate dimer is more ionizable in negative mode ESI compared to the monomer. We do not expect a large ionization difference between 2MGA-nitrate and 2MGA as the carboxyl moiety is believed to be the charge carrier for this compound in negative mode ESI with aqueous-based solvents. ${ }^{59}$

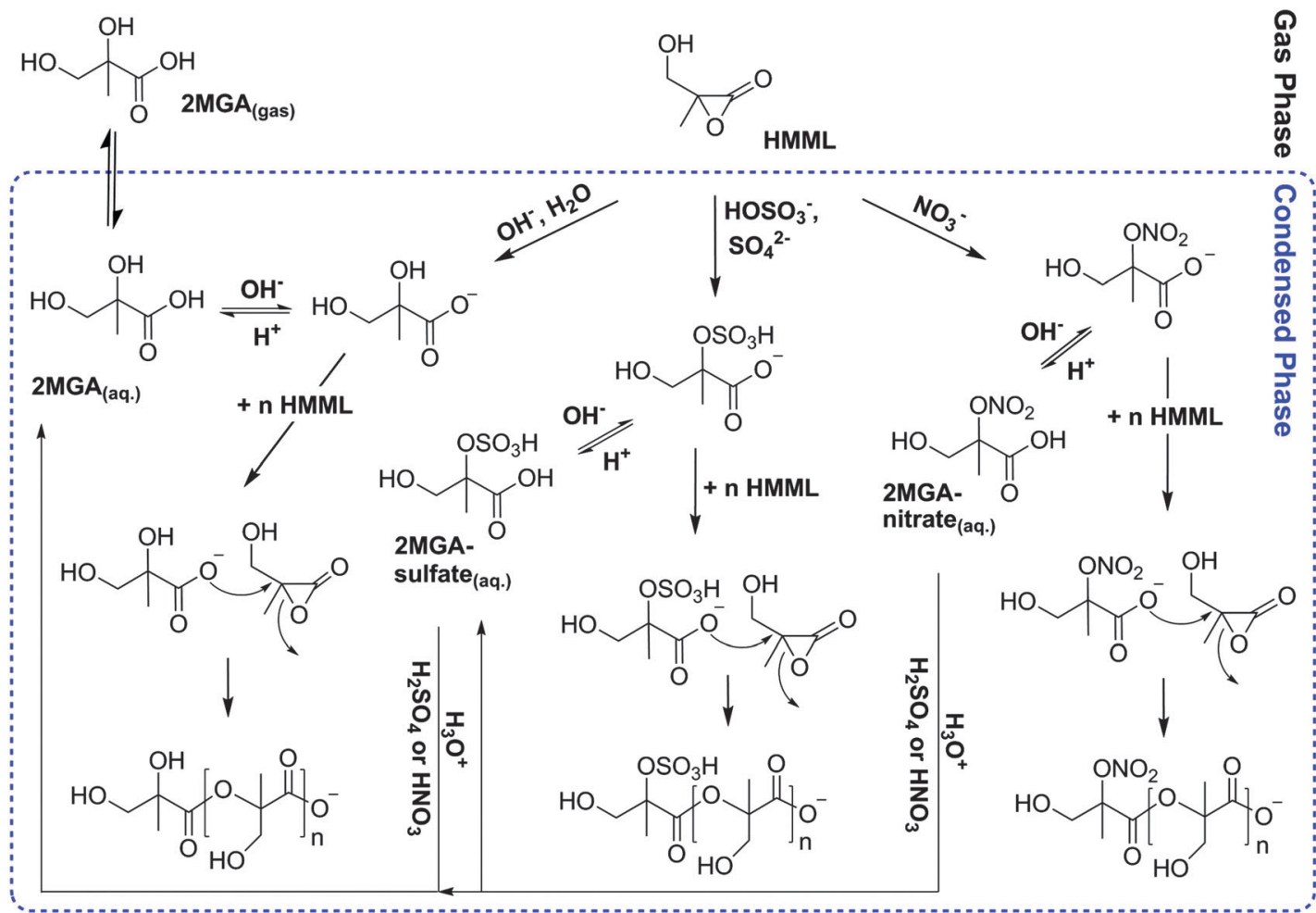

Fig. 10 Mechanism of SOA production from HMML (the blue dashed area represents the condensed phase). When particle liquid water is high, the main fate of HMML is reaction with water to produce monomeric 2MGA or sulfate and nitrate ions to produce 2MGA-sulfate and 2MGA-nitrate, respectively. The 2MGA monomer is volatile enough to re-partition to the gas phase. When the SOA composition is higher in organics than water, the main fate of HMML is reaction with its condensed-phase derivatives, producing low-volatility polyesters that increase SOA mass. Hydrated particles with higher free acidity may favour the monomeric form of 2MGA by neutralizing the carboxylate and hydrolyzing the sulfate and nitrate esters, possibly suppressing SOA growth. 
The combined mass of the SOA from these organic acid and hetero-atom compounds in the $85 \% \mathrm{RH}$ experiment, however, is lower than the mass of 2MGA in the gas phase (Fig. 7).

These aerosol phase HR-MS observations are consistent with earlier suggestions that relative humidity plays a role in modifying the composition and yield of isoprene-derived high- $\mathrm{NO}_{x}$ SOA. ${ }^{60,61}$ However, previous works did not study 2 MGA particle/ gas partitioning and discussions were framed with respect to poly-condensation reactions (e.g., a Fisher type esterification) a hypothesis that is not consistent with the present data. Furthermore, it has been recently shown that Fisher type esterification is too slow to form 2MGA oligomers under standard conditions. ${ }^{62}$ This does not, however, preclude condensation reactions from occurring when aerosol particles or cloud/fog droplets are evaporated. ${ }^{63,64}$ In light of the gas-phase mechanism of MPAN $+\mathrm{OH}$ presented here, the molecular driving force behind the effect of $\mathrm{RH}$ on MPAN aerosol composition and yield can now be understood in terms of lactone polymerization.

Fig. 10 shows the proposed mechanism with which HMML is converted to SOA and gas-phase 2MGA. Lactones are wellknown to produce polyesters via polyaddition. ${ }^{65}$ We suspect that, in nature, the anionic ring opening polymerization scheme is the active mechanism. Nucleophilic attack at the $\mathrm{sp}^{3}$ carbon is dominant for $\alpha$-lactones, ${ }^{66}$ partly due to the stability of the carboxylate (estimated to be only $\sim 10 \mathrm{kcal} \mathrm{mol}^{-1}$ higher in energy than the $\alpha$-lactone). ${ }^{67}$ The propagated carboxylate can repeatedly add HMML under low RH conditions, where its main fate is reaction with organics that coat the particle. In ambient SOA, ring-opening initiators may be aqueous inorganic anions or myriad carboxylates that are present in the condensed phase. When liquid water is in excess (as is mainly the case in the lower troposphere), it appears the main fate of HMML is reaction with $\mathrm{H}_{2} \mathrm{O}$, aqueous sulfate, or aqueous nitrate, and not with organics. Because the organonitrate is more easily hydrolyzed, the major product of the reaction under typical atmospheric conditions is expected to be monomeric 2MGA and 2MGA sulfate. The 2MGA may re-partition into the gas phase, leading to significantly reduced SOA mass yields.

\section{Atmospheric implications}

The representation of MPAN oxidation in atmospheric models has important ramifications. Thus far, only the proposed MAE mechanism (i.e., reactive uptake) has been considered for modelling SOA formation and framing field observations. ${ }^{68,69}$ Previously modelled SOA formation from MAE increases with particle acidity, while simulations based on HMML are expected to exhibit a different temporal and spatial variability. Pye et al. ${ }^{68}$ used the HMML and MAE yields suggested by Lin et al. ${ }^{18}$ (57\% and $21 \%$, respectively); however, both compounds were assigned to have the acid-catalysed heterogeneous fate of MAE (i.e., essentially converting HMML mass to MAE). The observed and predicted SOA from MPAN deviates from the $1: 1$ relationship in that work, likely a result of the assumed
SOA mechanism. Fig. 8 and the mechanisms in Fig. 10 suggest a more complex impact of particle free acidity. For example, in conditions when particle free acidity is high, the neutral form of 2MGA will be favored and the organosulfate/organonitrate may hydrolyze more rapidly. ${ }^{70}$ Both situations will enhance the abundance of 2MGA in the gas phase at the expense of lower-volatility derivatives that are important for SOA formation and growth.

The regional atmospheric importance of MPAN will vary with $\mathrm{NO}_{2} / \mathrm{NO}$ ratio and isoprene emissions. Kjaergaard et al. ${ }^{17}$ estimated that approximately $4 \mathrm{Tg}$ of HMML is produced per year (up to $0.8 \mu \mathrm{g} \mathrm{m}^{-3} \mathrm{day}^{-1}$ in the Southeast U.S.). However, whether the carbon from HMML is directed toward the formation of gaseous 2MGA or SOA will depend on atmospheric conditions and particulate matter characteristics. Typically, oligomers are not observed in ambient SOA and the mass concentrations of 2MGA and 2MGA-sulfate are low (e.g.,

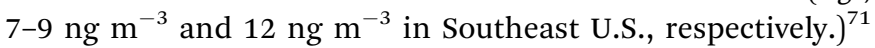
The low ambient observations in the Southeast US, a region characterized by higher particle liquid water and lower particle $\mathrm{pH},{ }^{72,73}$ are consistent with the HMML-derived SOA formation mechanism (Fig. 10). This work demonstrates that certain "SOA tracers" have more complex fates in nature than previously recognized. Interpreting the abundance of aqueous 2MGA and 2MGA-sulfate will require knowledge of physical parameters that may not be available for these compounds (e.g., Henry's Law coefficients, reaction coefficients, temperature and $\mathrm{pH}$-dependent accommodation). We expect that integrating the lactone mechanism into atmospheric models will produce a more accurate representation of the magnitude, temporal variation, and spatial distribution of isoprenederived organic compounds (whether in the gas or condensed phase) near anthropogenically-influenced regions.

\section{Acknowledgements}

We acknowledge funding from the U.S. National Science Foundation (NSF) Division of Atmospheric and Geospace Sciences (AGS) grant AGS-1240604 and the U.S. Department of Energy (DOE) grant DE-SC0006626. TBN is supported by the NSF postdoctoral research fellowship (PRF) award AGS1331360. We thank Dr. Dennis Fitz (UC Riverside) for assistance with the Fitz Aerometric $\mathrm{NO}_{2} / \mathrm{APN}$ instrument, Matthew Coggon (Caltech) for AMS data collection and processing, Dr. Nathan F. Dalleska (Caltech Global Environmental Center) for help with the HR-MS analysis software and for use of the $\mathrm{pH}$ probe, and Dr. Avram Gold and Dr. Zhenfa Zhang (University of North Carolina) for assistance in synthesizing MAE. The HPLC-UV/Vis-ESI/HRMS analysis was performed at the W. R. Wiley Environmental Molecular Sciences Laboratory (EMSL), a national scientific user facility sponsored by the DOE's Office of Biological and Environmental Research and located at PNNL. PNNL is operated for the DOE by Battelle Memorial Institute under contract \#DE-AC06-76RL0 1830. 


\section{References}

1 J. Mao, F. Paulot, D. J. Jacob, R. C. Cohen, J. D. Crounse, P. O. Wennberg, C. A. Keller, R. C. Hudman, M. P. Barkley and L. W. Horowitz, J. Geophys. Res., 2013, 118, 2013JD020231.

2 S. E. Pusede and R. C. Cohen, Atmos. Chem. Phys., 2012, 12, 8323-8339.

3 E. C. Browne and R. C. Cohen, Atmos. Chem. Phys., 2012, 12, 11917-11932.

4 A. W. Rollins, E. C. Browne, K.-E. Min, S. E. Pusede, P. J. Wooldridge, D. R. Gentner, A. H. Goldstein, S. Liu, D. A. Day, L. M. Russell and R. C. Cohen, Science, 2012, 337, 1210-1212.

5 L. Xu, H. Guo, C. M. Boyd, M. Klein, A. Bougiatioti, K. M. Cerully, J. R. Hite, G. Isaacman-VanWertz, N. M. Kreisberg, C. Knote, K. Olson, A. Koss, A. H. Goldstein, S. V. Hering, J. de Gouw, K. Baumann, S.-H. Lee, A. Nenes, R. J. Weber and N. L. Ng, Proc. Natl. Acad. Sci. U. S. A., 2015, 112, 37-42.

6 A. H. Goldstein, C. D. Koven, C. L. Heald and I. Y. Fung, Proc. Natl. Acad. Sci. U. S. A., 2009, 106, 8835-8840.

7 A. G. Carlton and B. J. Turpin, Atmos. Chem. Phys., 2013, 13, 10203-10214.

8 J. J. Orlando, G. S. Tyndall and S. E. Paulson, Geophys. Res. Lett., 1999, 26, 2191-2194.

9 I. Kourtchev, T. Ruuskanen, W. Maenhaut, M. Kulmala and M. Claeys, Atmos. Chem. Phys., 2005, 5, 2761-2770.

10 E. O. Edney, T. E. Kleindienst, M. Jaoui, M. Lewandowski, J. H. Offenberg, W. Wang and M. Claeys, Atmos. Environ., 2005, 39, 5281-5289.

11 A. C. Ion, R. Vermeylen, I. Kourtchev, J. Cafmeyer, X. Chi, A. Gelencsér, W. Maenhaut and M. Claeys, Atmos. Chem. Phys., 2005, 5, 1805-1814.

12 T. B. Nguyen, J. Laskin, A. Laskin and S. A. Nizkorodov, Environ. Sci. Technol., 2011, 45, 6908-6918.

13 A. W. H. Chan, M. N. Chan, J. D. Surratt, P. S. Chhabra, C. L. Loza, J. D. Crounse, L. D. Yee, R. C. Flagan, P. O. Wennberg and J. H. Seinfeld, Atmos. Chem. Phys., 2010, 10, 7169-7188.

14 J. D. Surratt, S. M. Murphy, J. H. Kroll, N. L. Ng, L. Hildebrandt, A. Sorooshian, R. Szmigielski, R. Vermeylen, W. Maenhaut, M. Claeys, R. C. Flagan and J. H. Seinfeld, J. Phys. Chem. A, 2006, 110, 9665-9690.

15 M. Claeys, W. Wang, A. C. Ion, I. Kourtchev, A. Gelencser and W. Maenhaut, Atmos. Environ., 2004, 38, 4093-4098.

16 J. Surratt, A. W. H. Chan, N. C. Eddingsaas, M. Chan, C. L. Loza, A. J. Kwan, S. P. Hersey, R. C. Flagan, P. O. Wennberg and J. H. Seinfeld, Proc. Natl. Acad. Sci. U. S. A., 2010, 107, 6640-6645.

17 H. G. Kjaergaard, H. C. Knap, K. B. Ørnsø, S. Jørgensen, J. D. Crounse, F. Paulot and P. O. Wennberg, J. Phys. Chem. A, 2012, 116, 5763-5768.

18 Y.-H. Lin, H. Zhang, H. O. T. Pye, Z. Zhang, W. J. Marth, S. Park, M. Arashiro, T. Cui, S. H. Budisulistiorini, K. G. Sexton, W. Vizuete, Y. Xie, D. J. Luecken, I. R. Piletic, E. O. Edney, L. J. Bartolotti, A. Gold and J. D. Surratt, Proc. Natl. Acad. Sci. U. S. A., 2013, 110, 6718-6723.
19 F. Paulot, J. D. Crounse, H. G. Kjaergaard, A. Kurten, J. M. St. Clair, J. H. Seinfeld and P. O. Wennberg, Science, 2009, 325, 730-733.

20 D. Grosjean, E. L. Williams and E. Grosjean, Int. J. Chem. Kinet., 1993, 25, 921-929.

21 J. J. Orlando, G. S. Tyndall, S. B. Bertman, W. Chen and J. B. Burkholder, Atmos. Environ., 2002, 36, 1895-1900.

22 T. B. Nguyen, J. D. Crounse, R. H. Schwantes, A. P. Teng, K. H. Bates, X. Zhang, J. M. St. Clair, W. H. Brune, G. S. Tyndall, F. N. Keutsch, J. H. Seinfeld and P. O. Wennberg, Atmos. Chem. Phys., 2014, 14, 13531-13549.

23 J. M. Roberts and S. B. Bertman, Int. J. Chem. Kinet., 1992, 24, 297-307.

24 S. P. Sander, D. Golden, M. Kurylo, G. Moortgat, P. Wine, A. Ravishankara, C. Kolb, M. Molina, B. Finlayson-Pitts and R. Huie, JPL Publication 06-2, Jet Propulsion Laboratory, Pasadena, 2006, http://jpldataeval.jpl.nasa.gov.

25 F. Drewnick, S. Hings, P. DeCarlo, J. Jayne, M. Gonin, K. Fuhrer, S. Weimer, J. Jimenez, K. Demerjian, S. Borrmann and D. Worsnop, Aerosol Sci. Technol., 2005, 39, 637-658.

26 J. M. St. Clair, D. C. McCabe, J. D. Crounse, U. Steiner and P. O. Wennberg, Rev. Sci. Instrum., 2010, 81, 094102.

27 J. D. Crounse, K. A. McKinney, A. J. Kwan and P. O. Wennberg, Anal. Chem., 2006, 78, 6726-6732.

28 T. B. Nguyen, J. D. Crounse, A. P. Teng, J. M. St. Clair, F. Paulot, G. M. Wolfe and P. O. Wennberg, Proc. Natl. Acad. Sci. U. S. A., 2015, 112, E392-E401.

29 L. Lee, A. P. Teng, P. O. Wennberg, J. D. Crounse and R. C. Cohen, J. Phys. Chem. A, 2014, 118, 1622-1637.

30 T. Su and W. J. Chesnavich, J. Chem. Phys., 1982, 76, 5183-5185.

31 A. L. Garden, F. Paulot, J. D. Crounse, I. J. MaxwellCameron, P. O. Wennberg and H. G. Kjaergaard, Chem. Phys. Lett., 2009, 474, 45-50.

32 W. Lindinger, A. Hansel and A. Jordan, Chem. Soc. Rev., 1998, 27, 347-354.

33 R. Atkinson, D. L. Baulch, R. A. Cox, J. N. Crowley, R. F. Hampson, R. G. Hynes, M. E. Jenkin, M. J. Rossi, J. Troe and I. Subcommittee, Atmos. Chem. Phys., 2006, 6, 3625-4055.

34 C. Canosa-Mas, M. King, D. Shallcross and R. Wayne, Phys. Chem. Chem. Phys., 1999, 1, 2411-2414.

35 J. L. Fry, D. C. Draper, K. C. Barsanti, J. N. Smith, J. Ortega, P. M. Winkler, M. J. Lawler, S. S. Brown, P. M. Edwards and R. C. Cohen, Environ. Sci. Technol., 2014, 48, 11944-11953.

36 M. Hallquist, I. Waengberg, E. Ljungstroem, I. Barnes and K.-H. Becker, Environ. Sci. Technol., 1999, 33, 553-559.

37 M. Spittler, I. Barnes, I. Bejan, K. J. Brockmann, T. Benter and K. Wirtz, Atmos. Environ., 2006, 40, S116-S127.

38 J. Gaffney, R. Bornick, Y.-H. Chen and N. Marley, Atmos. Environ., 1998, 32, 1445-1454.

39 S. B. Bertman and J. M. Roberts, Geophys. Res. Lett., 1991, 18, 1461-1464.

40 E. R. Stephens, The formation, reactions, and properties of peroxyacyl nitrates (PANs) in photochemical air pollution, Wiley, 1969.

41 Z.-w. An, R. D’Aloisio and C. Venturello, Synthesis, 1992, 273-275. 
42 E. P. Serjeant and B. Dempsey, Ionisation constants of organic acids in aqueous solution, Pergamon, 1979.

43 K. Makino, M. M. Mossoba and P. Riesz, J. Am. Chem. Soc., 1982, 104, 3537-3539.

44 G. Nouaime, S. Bertman, C. Seaver, D. Elyea, H. Huang, P. Shepson, T. Starn, D. Riemer, R. Zika and K. Olszyna, J. Geophys. Res., 1998, 103, 22463-22471.

45 B. Chuong and P. S. Stevens, Int. J. Chem. Kinet., 2004, 36, 12-25.

46 T. P. Riedel, Y.-H. Lin, S. H. Budisulistiorini, C. J. Gaston, J. A. Thornton, Z. Zhang, W. Vizuete, A. Gold and J. D. Surratt, Environ. Sci. Technol. Lett., 2015, 2, 38-42.

47 S. M. Saunders, D. L. Baulch, K. M. Cooke, M. J. Pilling and P. I. Smurthwaite, Int. J. Chem. Kinet., 1994, 26, 113-130.

48 G. Biskos, D. Paulsen, L. M. Russell, P. R. Buseck and S. T. Martin, Atmos. Chem. Phys., 2006, 6, 4633-4642.

49 G. Isaacman, PhD thesis, University of California, Berkeley, 2014.

50 A. Sorooshian, M.-L. Lu, F. J. Brechtel, H. Jonsson, G. Feingold, R. C. Flagan and J. H. Seinfeld, Environ. Sci. Technol., 2007, 41, 4647-4654.

51 A. G. Carlton, B. J. Turpin, H. J. Lim, K. E. Altieri and S. Seitzinger, Geophys. Res. Lett., 2006, 33, L06822, DOI: 10.1029/02005gl025374.

52 T. Christoffersen, J. Hjorth, O. Horie, N. Jensen, D. Kotzias, L. Molander, P. Neeb, L. Ruppert, R. Winterhalter and A. Virkkula, Atmos. Environ., 1998, 32, 1657-1661.

53 S. Koch, R. Winterhalter, E. Uherek, A. Kolloff, P. Neeb and G. K. Moortgat, Atmos. Environ., 2000, 34, 4031-4042.

54 A. K. Bertram, S. T. Martin, S. J. Hanna, M. L. Smith, A. Bodsworth, Q. Chen, M. Kuwata, A. Liu, Y. You and S. R. Zorn, Atmos. Chem. Phys., 2011, 11, 10995-11006.

55 R. E. O’Brien, B. Wang, S. T. Kelly, N. Lundt, Y. You, A. K. Bertram, S. R. Leone, A. Laskin and M. K. Gilles, Environ. Sci. Technol., 2015, 49, 4995-5002.

56 B. Wang and A. Laskin, J. Geophys. Res., 2014, 119, 3335-3351.

57 A. Laskin, R. C. Moffet, M. K. Gilles, J. D. Fast, R. A. Zaveri, B. Wang, P. Nigge and J. Shutthanandan, J. Geophys. Res., 2012, 117, D15302.

58 R. Szmigielski, J. D. Surratt, R. Vermeylen, K. Szmigielska, J. H. Kroll, N. L. Ng, S. M. Murphy, A. Sorooshian, J. H. Seinfeld and M. Claeys, J. Mass Spectrom., 2007, 42, 101-116.

59 M. Yamashita and J. B. Fenn, J. Phys. Chem., 1984, 88, 4671-4675.
60 T. B. Nguyen, P. J. Roach, J. Laskin, A. Laskin and S. A. Nizkorodov, Atmos. Chem. Phys., 2011, 11, 6931-6944.

61 H. Zhang, J. D. Surratt, Y. H. Lin, J. Bapat and R. M. Kamens, Atmos. Chem. Phys., 2011, 11, 6411-6424.

62 A. Birdsall, C. Zentner and M. Elrod, Atmos. Chem. Phys., 2013, 13, 3097-3109.

63 D. O. De Haan, L. N. Hawkins, J. A. Kononenko, J. J. Turley, A. L. Corrigan, M. A. Tolbert and J. L. Jimenez, Environ. Sci. Technol., 2011, 45, 984-991.

64 T. B. Nguyen, P. B. Lee, K. M. Updyke, D. L. Bones, J. Laskin, A. Laskin and S. A. Nizkorodov, J. Geophys. Res., 2012, 117, D01207, DOI: 10.1029/02011JD016944.

65 A. Löfgren, A.-C. Albertsson, P. Dubois and R. Jérôme, J. Macromol. Sci., Chem., 1995, 35, 379-418.

66 A. Greenberg and J. F. Liebman, Kinetic and Thermodynamic Stability, Organic Chemistry: A Series of Monographs, Academic Press, 1978, vol. 38, ch. 5, pp. 225-341.

67 J. F. Liebman and A. Greenberg, J. Org. Chem., 1974, 39, 123-130.

68 H. O. T. Pye, R. W. Pinder, I. R. Piletic, Y. Xie, S. L. Capps, Y.-H. Lin, J. D. Surratt, Z. Zhang, A. Gold, D. J. Luecken, W. T. Hutzell, M. Jaoui, J. H. Offenberg, T. E. Kleindienst, M. Lewandowski and E. O. Edney, Environ. Sci. Technol., 2013, 47, 11056-11064.

69 D. R. Worton, J. D. Surratt, B. W. LaFranchi, A. W. H. Chan, Y. Zhao, R. J. Weber, J.-H. Park, J. B. Gilman, J. de Gouw, C. Park, G. Schade, M. Beaver, J. M. S. Clair, J. Crounse, P. Wennberg, G. M. Wolfe, S. Harrold, J. A. Thornton, D. K. Farmer, K. S. Docherty, M. J. Cubison, J.-L. Jimenez, A. A. Frossard, L. M. Russell, K. Kristensen, M. Glasius, J. Mao, X. Ren, W. Brune, E. C. Browne, S. E. Pusede, R. C. Cohen, J. H. Seinfeld and A. H. Goldstein, Environ. Sci. Technol., 2013, 47, 11403-11413.

70 K. S. Hu, A. I. Darer and M. J. Elrod, Atmos. Chem. Phys., 2011, 11, 8307-8320.

71 Y. H. Lin, E. M. Knipping, E. S. Edgerton, S. L. Shaw and J. D. Surratt, Atmos. Chem. Phys., 2013, 13, 8457-8470.

72 H. Guo, L. Xu, A. Bougiatioti, K. M. Cerully, S. L. Capps, J. R. Hite, A. G. Carlton, S. H. Lee, M. H. Bergin, N. L. Ng, A. Nenes and R. J. Weber, Atmos. Chem. Phys. Discuss., 2014, 14, 27143-27193.

73 T. K. V. Nguyen, M. D. Petters, S. R. Suda, H. Guo, R. J. Weber and A. G. Carlton, Atmos. Chem. Phys., 2014, 14, 10911-10930. 